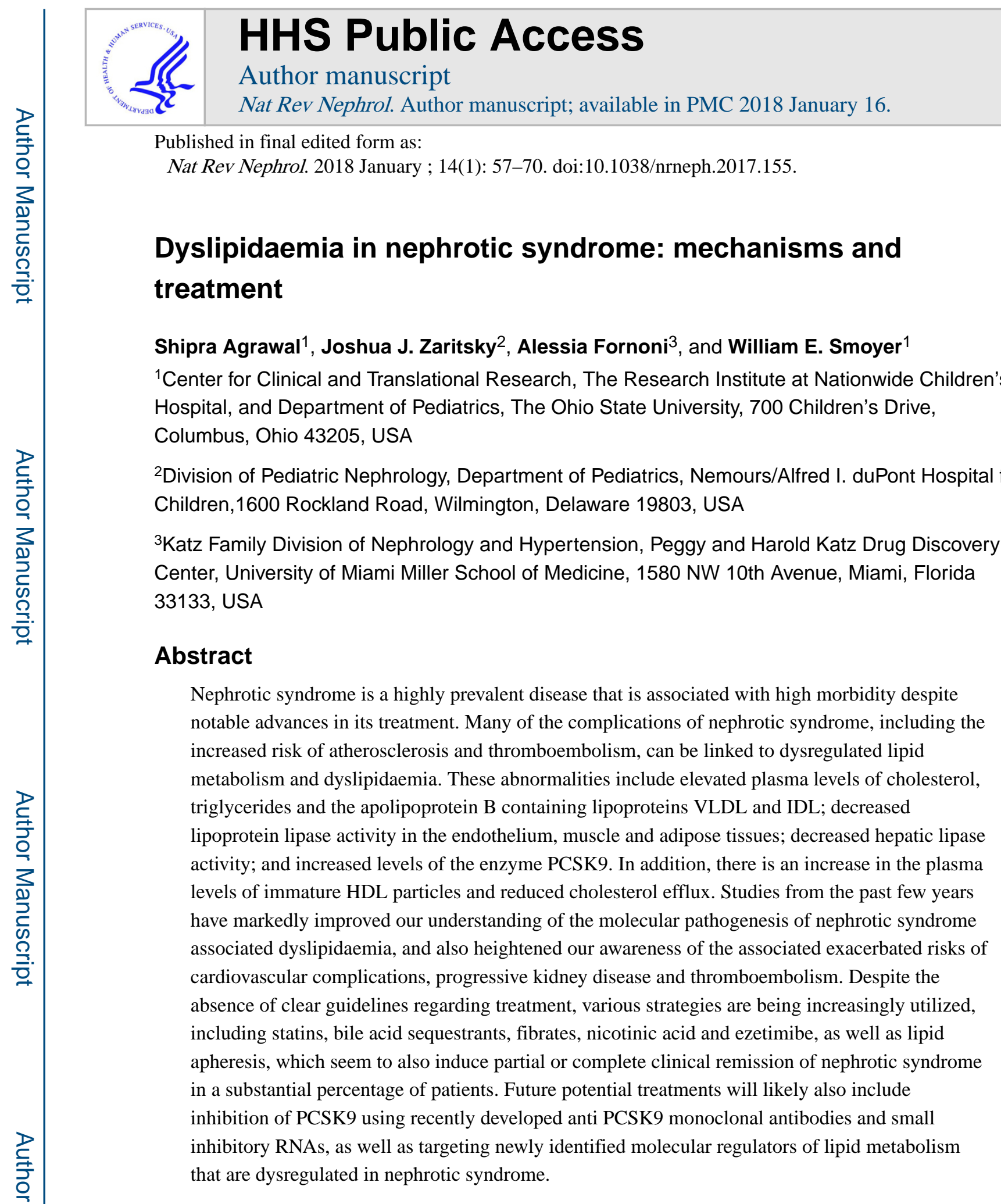

Published in final edited form as:

Nat Rev Nephrol. 2018 January ; 14(1): 57-70. doi:10.1038/nrneph.2017.155.

\title{
Dyslipidaemia in nephrotic syndrome: mechanisms and treatment
}

\author{
Shipra Agrawal ${ }^{1}$, Joshua J. Zaritsky ${ }^{2}$, Alessia Fornoni ${ }^{3}$, and William E. Smoyer \\ ${ }^{1}$ Center for Clinical and Translational Research, The Research Institute at Nationwide Children's \\ Hospital, and Department of Pediatrics, The Ohio State University, 700 Children's Drive, \\ ${ }^{2}$ Division of Pediatric Nephrology, Department of Pediatrics, Nemours/Alfred I. duPont Hospital for \\ Kamily Division of Nephrology and Hypertension, Peggy and Harold Katz Drug Discovery \\ er Miami Miller School or Medicine,
}

Abstract

Nephrotic syndrome is a highly prevalent disease that is associated with high morbidity despite increased risk of atherosclerosis and thromboembolism, can be linked to dysregulated lipid metabolism and dyslipidaemia. These abnormalities include elevated plasma levels of cholesterol, triglycerides and the apolipoprotein B containing lipoproteins VLDL and IDL; decreased ipoprotein lipase activity in the endothelium, muscle and adipose tissues; decreased hepatic lipase ivity; and increased levels of the enzyme PCSK9. In addition, there is an increase in the plasma levels of immature HDL particles and reduced cholesterol efflux. Studies from the past few years have markedly improved our understanding of the molecular pathogenesis of nephrotic syndrome associated dyslipidaemia, and also heightened our awareness of the associated exacerbated risks of m. Despite the absence of clear guidelines regarding treatment, various strategies are being increasingly utilized, including statins, bile acid sequestrants, fibrates, nicotinic acid and ezetimibe, as well as lipid apheresis, which seem to also induce partial or complete clinical remission of nephrotic syndrome in a substantial percentage of patients. Future potential treatments will likely also include inhibition of PCSK9 using recently developed anti PCSK9 monoclonal antibodies and small inhibitory RNAs, as well as targeting newly identified molecular regulators of lipid metabolism that are dysregulated in nephrotic syndrome.

Correspondence to W.E.S. william.smoyer@ nationwidechildrens.org.

Author contributions

All authors contributed to researching data for the article, and writing, reviewing and editing the article before submission.

Competing interests statement

The authors declare that they have no competing interests. 
Nephrotic syndrome is one of the most common kidney diseases in children and adults, and is characterized by massive proteinuria, oedema and hypoalbuminaemia ${ }^{1}$. The annual incidence and prevalence of nephrotic syndrome in children are 2-7 new cases and 16 cases per 100,000 children, respectively, and in adults the yearly incidence is three new cases per 100,000 adults ${ }^{2-5}$. It is difficult to establish the prevalence of nephrotic syndrome in adults, as it usually results from an underlying disease. Although the majority of children and adults respond to initial treatment with glucocorticoids by entering into clinical remission, a substantial proportion of patients ( $20 \%$ of children and $50 \%$ of adults) either present with or subsequently develop clinical steroid resistance during the course of their disease $e^{6,7}$. Failure to enter clinical remission greatly increases a patient's risk of various complications. These complications may result from persistence of the nephrotic state and/or from exposure to the relatively toxic alternative therapies that are used to induce remission.

The primary pathology associated with nephrotic syndrome is injury to podocytes and the glomeruli ${ }^{1,8}$. However, the complications of both the disease and its treatment are farreaching. Major complications include infections, acute kidney injury (AKI) and thromboembolisms ${ }^{9-12}$. A 2015 study found that AKI occurred in 58\% of 336 children admitted to hospital for nephrotic syndrome and in $~ 50 \%$ of 615 hospitalized children with nephrotic syndrome ${ }^{12}$. After infections and AKI, thromboembolism is also considered to be the most common, major complication of nephrotic syndrome ${ }^{13-16}$. Children with nephrotic syndrome develop thromboembolism at a rate of $2.8 \%$, whereas adults have a much higher rate of $26.7 \%$. Thromboembolism is particularly prevalent in patients with membranous nephropathy, affecting as many as $37 \%$ of adults and $25 \%$ of children ${ }^{14}$. Thromboembolism in patients with nephrotic syndrome is thought to be due to increased urinary loss of antithrombotic factors and increased hepatic production of prothrombotic factors ${ }^{13,14,16}$.

Dysregulated lipid metabolism leading to dyslipidaemia is an often under-recognized, but nearly universal, complication of persistent nephrotic syndrome. Although elevated serum levels of cholesterol and triglycerides have been noted since the early descriptions of nephrotic syndrome, the long-term consequences of prolonged dyslipidaemia in nephrotic syndrome remain relatively poorly understood. Whereas adults with nephrotic syndrome have a markedly increased risk of both myocardial infarction and coronary death compared with that of healthy individuals, very few data are available regarding these risks in children. Consequently, the dyslipidaemia of nephrotic syndrome is probably often under-treated, particularly in children, of whom very few would have pre-existing hyperlipidaemia from other causes. However, hyperlipidaemia has been associated with an increased risk of both accelerated cardiovascular disease and progressive kidney disease, and persistent nephrotic syndrome is characteristically accompanied by moderate to severe dyslipidaemia. In this Review, we summarize recent advances in our understanding of the characteristics, molecular pathogenesis and consequences of dyslipidaemia in patients with nephrotic syndrome, as well as the evidence supporting current and potential future treatments of nephrotic syndrome-associated dyslipidaemia. 


\section{Dyslipidaemia in nephrotic syndrome}

\section{Characteristics of dyslipidaemia}

Lipoproteins are the major carriers of lipids in the blood and they participate in three major pathways that are responsible for the generation and transport of lipids within the body (TABLE 1) - namely, the exogenous pathway, the endogenous pathway and the reverse cholesterol transport pathway (FIG. 1). Lipid and lipoprotein metabolism is altered in nephrotic syndrome, with or without chronic kidney disease (CKD) ${ }^{17}$ (FIG. 2). The extent of altered lipid metabolism in nephrotic syndrome correlates with the magnitude of proteinuria. In particular, the plasma concentrations of cholesterol, triglycerides and apolipoprotein B (ApoB)-containing lipoproteins (including very low-density lipoprotein (VLDL), intermediate-density lipoprotein (IDL) and lipoprotein(a)) are all elevated in nephrotic syndrome. The concentration of high-density lipoprotein (HDL) cholesterol ${ }^{17}$ and the content of ApoA-I and ApoA-II apolipoproteins ${ }^{18}$ are very similar in healthy individuals and in patients with nephrotic syndrome. However, the efficiency of HDL particles in causing cholesterol efflux from peripheral tissues has yet to be studied in nephrotic syndrome, but is of interest as cholesterol efflux has been shown to be impaired in patients with diabetic nephropathy ${ }^{19}$. In fact, not only the total amount, but also the composition and function of lipoproteins are markedly altered in patients with nephrotic syndrome, with substantial increases in the levels of ApoA-I, ApoA-IV, ApoB, ApoC and ApoE, as well as in the ratio of ApoC-III to ApoC-II ${ }^{18}$. These changes in serum lipids and lipoproteins in patients with nephrotic syndrome are primarily a result of their impaired clearance and, to a lesser extent, their altered biosynthesis. In fact, although nephrotic syndrome can affect LDL synthesis ${ }^{20}$, the levels of most ApoB-containing lipoproteins are altered owing to decreased clearance ${ }^{21}$. Albumin metabolism was originally thought to be linked to hyperlipidaemia in nephrotic syndrome; however, the link between hepatic lipogenesis and albumin synthesis has been challenged by data from elegant studies suggesting that proteinuria, and not albumin synthesis, is linked to hyperlipidaemia in nephrotic rats ${ }^{22}$. The composition of lipoproteins can also be affected in nephrotic syndrome associated with CKD, because the activity of enzymes such as lecithin-cholesterol acyltransferase (LCAT) is reduced, whereas enzymes such as plasma cholesteryl ester transfer protein (CETP) are activated, resulting in the production of immature $\mathrm{HDL}^{23}$.

Severe hypertriglyceridaemia is another important lipid abnormality in patients with nephrotic syndrome, and recent discoveries have identified angiopoietin-related protein 4 (ANGPTL4) and the extent of its sialylation as attractive therapeutic targets for reducing proteinuria and hypertriglyceridaemia in these patients ${ }^{24}$. In addition, the presence of other diseases, as well as the use of treatments to reduce proteinuria and the progression of CKD, might worsen dyslipidaemia in affected patients. The lipid abnormalities observed in patients with proteinuric disorders who are in the early stages of CKD are clinically relevant, as they might actively contribute to the increased cardiovascular morbidity and mortality of these patients, and therefore early identification and treatment of these lipid abnormalities is important ${ }^{25}$. 


\section{Pathogenesis of dyslipidaemia}

Triglycerides, VLDL and fatty acid metabolism-VLDL is an important vehicle for the delivery of fatty acids to several tissues, primarily muscle and adipose tissue, where the fatty acids serve as an energy source (FIG. 1). On arrival in peripheral tissues, removal of fatty acids from VLDL by lipoprotein lipase (LPL) results in the formation of IDL, which is then cleared from the circulation by LDL receptor-related protein 1 (LRP1)-mediated endocytosis by hepatocytes. In addition to LRP1, the LDL receptor, liver proteoglycans and plasminogen receptor contribute to catabolism of lipoprotein(a) and hepatic uptake of ApoB and $A p o A^{26,27}$. Furthermore, differences in the affinity of ApoE proteins for the receptors responsible for lipoprotein clearance owing to different $A P O E$ genotypes affects lipoprotein(a) catabolism, possibly owing to competition between lipoprotein(a) and ApoE for the same receptors ${ }^{28}$. The levels of both IDL and VLDL are increased in patients with nephrotic syndrome, primarily owing to defective LPL activity and decreased hepatic lipase activity $^{21}$. For decades, the dogma was that LPL, which contains positively charged heparinbinding domains, binds to negatively charged heparin sulfate proteoglycans in the glycocalyx coating of blood vessels ${ }^{29,30}$. However, it is now established that the binding of LPL to heparan sulfate proteoglycans on endothelial cells occurs via endothelium-derived glycosylphosphatidylinositol-anchored HDL-binding protein 1 (GPIHBP1) ${ }^{31}$. Interestingly, GPIHBP1 is downregulated in patients with nephrotic syndrome ${ }^{32}$. Furthermore, the loss of LPL activators in patients with nephrotic syndrome is associated with increased glomerular basement membrane permeability, resulting in hyperlipidaemia ${ }^{33}$. In addition to downregulation of LPL activity, nephrotic syndrome is also characterized by downregulation of hepatic lipase activity, which contributes to decreased clearance of IDL and hypertriglyceridaemia. Furthermore, upregulation of ANGPTL4 levels in nephrotic syndrome, which is driven primarily by circulating free fatty acids ${ }^{34}$, may inactivate LPL by converting active LPL dimers into inactive monomers ${ }^{35}$ or by acting as a reversible noncompetitive inhibitor of $\mathrm{LPL}^{36}$. The reduced plasma clearance of VLDL in nephrotic syndrome may be linked to suppression of VLDL receptor expression, as was described in a rat model of nephrotic syndrome ${ }^{37}$. Fatty acid metabolism is also altered in nephrotic syndrome, as there is increased expression of key enzymes involved in fatty acid biosynthesis, including acetyl-CoA carboxylase and fatty acid synthase, and downregulation of fatty acid catabolism in the liver ${ }^{38}$. Triglyceride-rich, ApoB-containing lipoproteins, such as VLDL, may have atherogenic properties and increase the risk of coronary events independently of $\mathrm{LDL}^{39}$. The levels of ApoC-II and ApoC-III are elevated in patients with nephrotic syndrome ${ }^{40}$, although they return to normal within 4 weeks after normalization of the levels of urinary protein, suggesting that the elevated ApoC-II and ApoC-III levels are unlikely to contribute to the development of nephrotic syndrome ${ }^{41}$. However, the finding that ApoC-II may contribute to a new form of amyloidosis that primarily affects the kidney in humans is once more challenging the cause and effect relationship between ApoC-II and nephrotic syndrome ${ }^{42}$. A potential role for ApoA-V in nephrotic syndrome should also be investigated further, as the level of ApoA-V is higher in patients with diabetes and proteinuria than in patients with diabetes without proteinuria ${ }^{43}$.

Cholesterol metabolism: the role of LDL and HDL_Both enhanced production and impaired catabolism of LDL contribute to the increased LDL and cholesterol levels observed 
in patients with nephrotic syndrome. In addition, increased expression of proprotein convertase subtilisin/kexin type 9 (PCSK9) results in increased degradation of the LDL receptor and decreased LDL uptake by the liver ${ }^{44,45}$. Genetic ablation of podocytes in mice and treatment of mice with nephrotoxic serum cause hypercholesterolaemia and lead to increased levels of PCSK9 (REFS 45,46). Interestingly, hepatocyte-specific deletion of PCSK9 protects mice from nephrotoxic serum-induced hyperlipidaemia ${ }^{47}$. Furthermore, the elevated plasma levels of both cholesterol and PCSK9 detected in patients with active nephrotic syndrome have been reported to return to normal levels upon remission of disease $\mathrm{e}^{47}$. Hypercholesterolaemia and increased LDL levels occur in conjunction with upregulation of the expression and activity of liver acetyl-CoA acetyltransferase 2 (ACAT2), which results in enhanced esterification of cholesterol and a reduction in the level of intracellular free cholesterol ${ }^{48}$. Cholesterol synthesis via 3-hydroxy-3-methylglutaryl-CoA (HMG-CoA) reductase is also increased in experimental models of nephrotic syndrome ${ }^{49}$. Evidence also suggests that LDL oxidation in nephrotic syndrome might be augmented by lipoprotein(a) $)^{50}$, the level of which is increased in nephrotic syndrome ${ }^{51}$. Accumulation of oxidized LDL, IDL and chylomicron remnants stimulates monocytes and macrophages to release proin ammatory cytokines and chemokines and accelerates in ammation ${ }^{52}$, which may in turn promote the progression of CKD.

Patients with nephrotic syndrome can present with variable levels of HDL cholesterol, although the ratio of HDL cholesterol to total cholesterol is frequently decreased ${ }^{53}$. HDL is the main lipoprotein involved in cholesterol efflux from peripheral organs, as well as in the delivery of cholesterol to hepatocytes to be converted into bile acids (FIG. 1). The principal role of HDL is to promote cholesterol efflux, primarily via the membrane-associated transporters ATP-binding cassette subfamily A member 1 (ABCA1) and ATP-binding cassette subfamily $\mathrm{G}$ member $1(\mathrm{ABCG} 1)^{54}$. In addition to the induction of reverse cholesterol transport, HDL also has antioxidant activities and anti-inflammatory properties $^{55,56}$, and protects against endothelial dysfunction by binding to scavenger receptor B1 to activate endothelial nitric oxide synthase ${ }^{57}$. In nephrotic syndrome, in addition to a change in the HDL cholesterol:total cholesterol ratio, the maturation of cholesterol ester-poor $\mathrm{HDL}_{3}$ to cholesterol ester-rich $\mathrm{HDL}_{2}$ is often impaired ${ }^{58}$, suggesting impaired reverse cholesterol transport could be a key component of nephrotic syndrome and contribute to its associated vascular complications. Although extensively reviewed elsewhere ${ }^{59}$, new experimental studies suggest that improvement in cholesterol efflux via $\mathrm{ABCA} 1$ is also associated with improved proteinuria and renal failure in experimental models of focal segmental glomerulosclerosis ${ }^{60}$. Of note, this last study challenges the longheld idea that impaired HDL function is a consequence, rather than a cause, of proteinuria in nephrotic syndrome.

Lipoid nephrosis and foamy podocytes-Although the association between altered lipid metabolism and proteinuria has been extensively studied, it remains unclear whether dyslipidaemia actually contributes to kidney disease (FIG. 3). Similar to atherosclerosis, the effect of dyslipidaemia on decreased kidney function was first advocated as the 'lipid nephrotoxicity' hypothesis by Moorhead et al. in 1982 (REF. 33). In fact, minimal change disease was also originally defined as 'lipoid nephrosis', based on the presence of foamy 
cells in kidney biopsy samples ${ }^{61}$, although the identity of these cells (infiltrating macrophages or resident glomerular cells) has never been established. In addition, data from studies in experimental models of focal segmental glomerulosclerosis support the concept that lipid infiltration and accumulation in primary glomerular cells might contribute to the pathogenesis of proteinuria ${ }^{60}$.

It is important to consider the evidence suggesting that altered lipid metabolism might have a pathophysiologic role in nephrotic syndrome. In fact, LDL apheresis has been reported to be an effective measure to reduce proteinuria and podocyte loss or excretion in patients with refractory nephrotic syndrome ${ }^{62}$, suggesting that renal cholesterol uptake via LDL and/or inflammatory responses to oxidized LDL might contribute to the development of proteinuria. With regard to reverse cholesterol transport, the notion that impaired cholesterol efflux and/or production of a non-functioning HDL is a cause, rather than a consequence, of proteinuria remains to be established, but is the subject of intense research. In the general population, elevated plasma concentrations of HDL cholesterol are associated with atheroprotective properties ${ }^{63-65}$, although raising the plasma HDL cholesterol concentration does not necessarily reduce cardiovascular risk ${ }^{66,67}$. However, the effects of HDL quantity and function were not discriminated in these studies. In addition, genetic variants associated with a higher HDL cholesterol concentration are not associated with a reduced risk of cardiovascular disease ${ }^{68}$. The failure to observe cardiovascular protection in multiple trials with inhibitors of cholesteryl ester transfer protein (CETP) should not discourage additional research in the field, as CETP inhibitors were developed to raise HDL levels, and not to increase the functionality of HDL. However, a clinical trial (NCT01841684) ${ }^{69}$ showed that the CETP inhibitor anacetrapib met its primary end point of reducing cardiovascular events in patients at risk of cardiac events who were already receiving a statin, compared with placebo $^{70}$. Further research is also necessary to determine if agents capable of increasing cholesterol efflux, such as HDL mimetic peptides or recombinant ApoA-I, might represent novel therapeutic strategies to treat patients with proteinuric kidney diseases and the atherosclerosis associated with these diseases. The fact that LCAT deficiency in fish eye disease results in a renal lipidosis that is associated with nephrotic range proteinuria strongly suggests that the elevated ratio of plasma unesterified cholesterol:total cholesterol observed in LCAT deficiency might contribute to the development of proteinuria ${ }^{71}$. Lipoprotein $\mathrm{X}$, an abnormal cholesterol-rich particle, might also contribute to renal disease in patients with LCAT deficiency ${ }^{72}$. Although more subtle than LCAT deficiency, the phenotype of patients with ABCA1 deficiency (Tangier disease) is also characterized by early atherosclerosis, very low HDL levels and mild proteinuria with foamy podocytes in kidney biopsy samples ${ }^{73}$. Therefore, novel therapeutic strategies aimed at reducing the acquired LCAT defect could potentially be effective in both reversing dyslipidaemia and slowing disease progression in patients with CKD.

Finally, the finding that a mutation in the enzyme sphingosine 1 phosphate lyase causes nephrotic syndrome ${ }^{74}$, together with the observation that enzymes involved in sphingolipid metabolism, such as acid sphingomyelinase-like phosphodiesterase 3b (SMPDL3b), might serve as modulators of lipid raft-dependent signalling 75 and might cause proteinuria, raises the important question of the potential role of sphingolipid modulators in causing podocyte injury in nephrotic syndrome. 
An important consideration in the treatment of nephrotic syndrome is that many of the treatments themselves contribute to abnormal lipid metabolism. Data on the efficacy of glucocorticoids for the treatment of dyslipidaemia are inconclusive - some observational data in adults suggest that glucocorticoids have only a minimal effect on serum lipid levels ${ }^{76}$, whereas several cross-sectional studies in patients with systemic lupus erythematosus demonstrated that administration of high doses of corticosteroids $(>10 \mathrm{mg}$ per day) is associated with elevated LDL and triglyceride levels ${ }^{77,78}$; however, the interpretation of these studies is complicated by the fact that many of the patients also had renal involvement. Glucocorticoids also increase VLDL levels directly (via increased hepatic production) and indirectly (via increased peripheral insulin resistance) ${ }^{79}$. Furthermore, inhibition of calcineurin activity using immunosuppressive drugs can lead to hypercholesterolaemia, and this effect is more prominent with ciclosporin treatment than with tacrolimus treatment ${ }^{80,81}$.

\section{Clinical consequences of dyslipidaemia}

There are numerous clinical consequences of dyslipidaemia in general, and in patients with nephrotic syndrome in particular (FIG. 2; TABLE 2). Dyslipidaemia can result in acceleration of atherosclerosis, as well as an increased risk of myocardial infarction or cerebrovascular accident (stroke). Furthermore, dyslipidaemia in nephrotic syndrome might have a causative role in the established increased risk of thrombosis associated with this disease. Dyslipidaemia is one of the dominant risk factors associated with atherothrombotic disorders. Atherosclerosis is usually accompanied by hyperreactive platelets that increase the risk of thrombosis, which is further exacerbated by dyslipidaemia ${ }^{82}$. Furthermore, the products of LDL oxidation enhance platelet activation and thrombus formation ${ }^{83}$.

Dyslipidaemia during nephrotic syndrome is also clearly associated with an increased risk of nephrotoxicity, which can manifest as progressive kidney disease ${ }^{33,82}$. This progressive kidney disease might result from the development of glomerulosclerosis, owing to podocyte injury and/or mesangial cell proliferation, as well as from proximal tubular cell injury (FIG. 3).

Of note, the presence of CKD, which often develops and/or progresses in patients with refractory nephrotic syndrome, further increases the risk of many of the complications, including dyslipidaemia (TABLE 2), as discussed below.

\section{Lipid nephrotoxicity}

The lipid nephrotoxicity hypothesis was proposed more than three decades ago, and proposes that hyperlipidaemia, in addition to proteinuria and hypoalbuminaemia, lead to adverse and injurious effects in kidneys and may cause glomerulosclerosis ${ }^{33,84}$. This hypothesis is supported by a number of observations, leading to the theory that the renal toxicity of filtered albumin is dependent on its lipid moiety ${ }^{85,86}$. Cholesterol and lipoprotein uptake are essential for the development, survival and growth of mammalian cells. In fact, in podocytes, lipid rafts contain many elements that are essential for the normal spatial organization and regulation of the slit diaphragm ${ }^{87}$. Excess accumulation of cellular cholesterol and lipids might, however, adversely affect cellular function and lead to toxicity and injury in podocytes as well as other cell types. In addition, during hyperlipidaemia, 
specific anatomical features of the glomeruli and renal interstitium probably make these the preferred locations for lipid deposition in the kidney ${ }^{84}$.

Mesangial cell proliferation-Within the kidney, the mesangial cells and the extracellular matrix within the glomerulus are most accessible to plasma lipoproteins such as LDL, as they are not separated from the capillary wall by an intervening basement membrane. Under normal conditions, mesangial cells take up LDL via a specific LDL receptor, and LDL is metabolized in a regulated manner. However, during hyperlipidaemia or extracellular matrix expansion, excess LDL is trapped in the extracellular matrix, where it is subject to oxidation, especially under conditions of mesangial cell stress, such as inflammatory, mechanical or ischaemic injury ${ }^{88,89}$. The oxidized LDL is taken up by receptors on mesangial cells, leading to the production of prostaglandin E2 and other cytotoxic agents, such as tumour necrosis factor (TNF), which further damage glomerular epithelial and endothelial cells, leading to sclerosis ${ }^{88,89}$. In addition to LDL and oxidized LDL, triglyceride-rich lipoproteins such as VLDL and IDL are also taken up by mesangial cells, leading to their proliferation and the release of several cytokines, such as IL-6, platelet derived growth factor (PDGF) and transforming growth factor- $\beta$ (TGF $\beta)^{89}$. In addition, the uptake of lipoproteins by both mesangial and endothelial cells is increased in the presence of lipoprotein lipase, which is localized to the glomerulus ${ }^{90,91}$. Furthermore, increased lipid accumulation owing to experimentally induced inflammatory stress results in the production of reactive oxygen species and increased expression of endoplasmic reticulum (ER) stress markers, both in the kidneys in vivo and in mesangial cells in vitro ${ }^{92}$.

Podocyte injury-The podocyte is the primary target of cellular injury in nephrotic syndrome ${ }^{8}$, both in minimal change disease and in focal segmental glomerulosclerosis, and podocyte loss and hypertrophy have a crucial role in the progression to end-stage renal disease. Lipids and the proteins that regulate lipids have a direct role in podocyte biology and pathophysiology via several different mechanisms, some of which we highlight here. Variants of APOL1, which encodes an important component of HDL and is expressed by podocytes, are widely associated with focal segmental glomerulosclerosis and podocytopathies ${ }^{93-95}$. Furthermore, antibodies directed against secretory phospholipase A2 receptor (PLA2R), which is also expressed by podocytes, have been detected in many patients with membranous nephropathy ${ }^{96,97}$. In addition, decreased expression of SMPDL3b has been observed in podocytes exposed to the sera of patients with recurrent focal segmental glomerulosclerosis ${ }^{75,98}$.

Several different free fatty acids bound to albumin have been shown to increase podocyte injury, by stimulating enhanced macropinocytosis by podocytes via lipid-binding G-proteincoupled receptors (GPCRs) ${ }^{99,100}$. GPCR signalling leads to the triggering of the $\mathrm{G} \beta / \mathrm{G} \gamma$ subunits and their dissociation, which in turn activate the RHO GTPases RAC1 and CDC42, leading to disruption of the actin cytoskeleton and dramatic changes in podocyte morphology. Furthermore, compared to mice fed control chow, those fed a high-fat diet develop elevated levels of free fatty acids and an increased susceptibility to adriamycininduced proteinuria, which underscores the effect of free fatty acids on podocyte function ${ }^{99,100}$. In addition, exposure of podocytes to albumin and its associated factors, such 
as fatty acids, has been shown to induce cell death, disruption of the cytoskeleton and injurious molecular responses, such as increased production of cyclooxygenase 2 (COX2) and several cytokines ${ }^{101}$. However, these injury responses are attenuated when podocytes are instead exposed to fatty acid-free albumin. Of note, the role of arachidonic acid in causing podocyte injury is highlighted by its ability to increase $\mathrm{COX} 2$ production when conjugated to fatty acid-free albumin. The marked reduction in proteinuria in a protein-overload model of renal injury in rats when the administered albumin was devoid of free fatty acids and other associated factors further demonstrates the in vivo relevance of albumin-bound fatty acids and other associated factors ${ }^{101}$. In particular, palmitic acid induces ER stress, apoptosis and necrosis in podocytes in a dose-dependent manner, which is enhanced by fatty acid oxidation ${ }^{102,103}$. Furthermore, the lipotoxic effects of palmitic acid accelerate glomerular disease through inflammation, oxidative stress and derangements of the actin cytoskeleton and decrease in the expression of the NPHS1 gene, which encodes the slit diaphragm protein nephrin, in podocytes ${ }^{104}$. In addition, stimulation of podocytes with TNF results in free cholesterol-mediated cell injury in a nuclear factor of activated $\mathrm{T}$ cells cytoplasmic 1 (NFATc1)-dependent manner ${ }^{60}$. Furthermore, this cholesterol-mediated injury is also dependent on ABCA1, which, as mentioned earlier, is a transporter responsible for cholesterol efflux from podocytes ${ }^{60}$. Together, these findings support a role for direct lipidinduced podocyte injury in the pathogenesis of nephrotic syndrome resulting from dyslipidaemia. In light of these results, future therapeutic interventions to reduce the effects of hyperlipidaemia in nephrotic syndrome should not only include interventions to lower lipid levels and prevent lipid oxidation, but also those to reduce lipid uptake by glomerular cells.

Tubulointerstitial disease-Nephrotic syndrome is associated with the development of renal tubular cell injury, and acute interstitial nephritis has been demonstrated in animal models of nephrotic syndrome ${ }^{105,106}$. This tubulointerstitial injury in nephrotic syndrome is characterized by the infiltration of macrophages and $\mathrm{T}$ lymphocytes into the tubulointerstitial space $^{105}$. Of note, fatty acids bound to albumin might be the main contributors to tubulointerstitial injury in a protein-overload model of proteinuria ${ }^{85}$. Furthermore, several studies have reported lipotoxic effects of saturated fatty acids in proximal tubular cell injury ${ }^{107-110}$ and stearoyl-CoA desaturase (SCD), an enzyme involved in free fatty acid metabolism, mediates the desaturation of saturated fatty acids and reduces the formation of lipid droplets and their lipotoxicity to cultured proximal tubule cells ${ }^{107}$. In addition, the renin-angiotensin system plays an important part in mediating ER stress in proximal tubule cells by saturated fatty acids ${ }^{108}$. Another study has demonstrated that the peroxisome proliferator-activated receptor-a (PPARa) agonist fenofibrate protects proximal tubule cells by inhibiting fatty acid toxicity mediated by nuclear factor- $\mathrm{kB}(\mathrm{NF}-\mathrm{\kappa B})^{109}$. Furthermore, circulating fatty acids bound to albumin can change the redox environment in the tubules, thus inducing a peroxide-mediated, redox-sensitive apoptosis in tubular cells ${ }^{110}$. Thus, these findings collectively provide evidence supporting a substantial role for direct lipid-induced cellular injury to both renal tubular cells and podocytes resulting from dyslipidaemia in nephrotic syndrome. 


\section{Importance of dyslipidaemia treatment}

Lipid abnormalities in the general population are associated with a reduction in kidney function. In addition, a strong relationship exists between hypercholesterolaemia and the risk of coronary artery disease, and multiple clinical trials have shown that a reduction in cholesterol or LDL in high-risk patients is associated with statistically and clinically significant reductions in cardiovascular mortality ${ }^{111,112}$. Hyperlipidaemia is also known to escalate the progression of glomerular injury, in part owing to accelerated atherosclerosis in the renal vascular system (TABLE 2). Consistent with accelerated atherosclerosis, patients with CKD have an increased prevalence of hyperlipidaemia and an increased risk of cardiovascular disease. Similarly, adults with nephrotic syndrome are at increased risk of myocardial infarction (relative risk (RR) 5.5) and coronary death (RR 2.8), compared to that of the general population ${ }^{113-118}$. By contrast, although myocardial infarction is extremely rare in children, a few case studies have reported myocardial infarctions in children with nephrotic syndrome ${ }^{119,120}$. Given the high morbidity associated with dyslipidaemia and the severity of the dyslipidaemia that occurs in patients with nephrotic syndrome, a clear need exists to prioritize aggressive treatment of dyslipidaemia in patients with chronic forms of nephrotic syndrome who do not enter remission. Below, we detail the available evidence for the efficacy of various treatments for dyslipidaemia in nephrotic syndrome in both adults and children, as well as future directions for treatment (TABLE 3).

\section{Treatment of dyslipidaemia}

\section{Lifestyle changes to treat dyslipidaemia}

Unfortunately, little evidence exists to guide the optimal treatment of dyslipidaemia in patients with nephrotic syndrome. Typically, the initial recommended treatment includes lifestyle changes that focus on diet, which is based on a study of 20 adult patients with longstanding severe proteinuria ${ }^{121}$. Compared with their values on the baseline diet, a soya-based vegetarian diet low in both fat and protein resulted in reductions in serum levels of cholesterol and apolipoprotein, but not in triglyceride levels, in these patients. Interestingly, proteinuria also decreased on the soya-based vegetarian diet. In a follow-up trial, 20 patients consumed either a soya-based diet or soya-based diet that included fish oil, for 2 months, followed by a crossover to the other treatment group ${ }^{122}$. The introduction of the soya-based diet again resulted in a decrease in hyperlipidaemia as well as proteinuria, without any measurable effect of fish oil supplementation. Despite the promising results from these trials, these results have not been replicated, and there is some question of whether the decrease in serum lipids in patients who consumed the soya-based vegetarian diet was the result of the lower dietary protein or the lower lipid intake.

Other lifestyle changes to combat hyperlipidaemia include weight loss in patients who are overweight, and increased aerobic exercise. However, these recommendations have never been formally studied in patients with nephrotic syndrome and are based largely on studies of healthy individuals. Dietary supplements, such as fish oils (discussed above) and policosanol, have been poorly studied in patients with nephrotic syndrome. Data supporting the best-studied supplement, omega- 3 fatty acids, in patients with nephrotic syndrome have shown a small decrease in serum triglycerides, with mixed effects on LDL levels ${ }^{123}$. 
Another study examining omega-3 fatty acid supplementation in patients with nephrotic syndrome demonstrated a decrease in postprandial chylomicrons ${ }^{124}$. Although promising, these results are based on studies with a small number of patients and with limited followup.

Pharmacological treatment of dyslipidaemia Statins-Statins are the most common pharmacological intervention to treat dyslipidaemia in patients with nephrotic syndrome. The mechanism of action of statins has been well characterized; statins competitively inhibit HMG-CoA reductase, reducing hepatic production of cholesterol, which in turn leads to increased uptake of LDL cholesterol from the blood. However, it is important to note that this class of drugs has been studied most extensively in patients with other diseases, with several large randomized controlled trials showing compelling reductions in the incidence of cardiovascular disease ${ }^{112}$.

The use of statins for the treatment of patients with nephrotic syndrome has been less wellstudied. Early studies found significant reductions in the serum levels of total cholesterol and LDL cholesterol, with lesser effects on the levels of triglycerides and apolipoproteins ${ }^{125,126}$. Pilot trials of atorvastatin treatment in children with nephrotic syndrome and pravastatin treatment in adults with nephrotic syndrome have been undertaken, but the results of these trials are not yet available (TABLE 3). However, a metaanalysis that included four randomized controlled trials comparing statin versus placebo versus no treatment showed limited effectiveness of statins in reducing dyslipidaemia ${ }^{127-131}$. Only one of these trials showed a significant increase in HDL levels after statin treatment ${ }^{127}$, and no differences were seen in total serum cholesterol, LDL or triglyceride levels. Fortunately, as noted in other studies, statins seem to be very well tolerated in patients with nephrotic syndrome and have a low adverse effect profile. Unfortunately, however, very few data have described the effects of statins on cardiovascular end points. Although statin treatment improved cardiovascular outcomes among patients with CKD who were not undergoing dialysis ${ }^{132}$, there are no studies showing a similar benefit in patients with nephrotic syndrome.

Second-line agents-In addition to statins, second-line agents that have been studied for the treatment of dyslipidaemia in nephrotic syndrome include bile acid sequestrants, fibrates, nicotinic acid and ezetimibe. Bile acid sequestrants, such as colestipol and cholestyramine, work by blocking the normal enterohepatic circulation of bile acids by preventing their enteral reabsorption. This inhibition in turn causes the upregulation of several hepatic enzymes responsible for bile acid synthesis. The end result is increased liver cholesterol catabolism and a compensatory increase in LDL absorption from the blood. Studies of bile acid sequestrants in the treatment of patients with other diseases have shown an approximately $25 \%$ reduction in serum levels of LDL cholesterol, with occasional increases in levels of triglycerides ${ }^{112}$. One study of colestipol treatment found a $30 \%$ decrease in serum levels of LDL cholesterol in patients with nephrotic syndrome ${ }^{133}$. Another small crossover trial of 10 patients with nephrotic syndrome compared treatment with cholestyramine versus simvastatin, and found a decrease in LDL cholesterol levels of 19\% 
versus $39 \%$, respectively ${ }^{125}$. Unfortunately, the bile sequestrants have a high rate of gastrointestinal adverse effects, which often limits their use.

Fibrates, such as gemfibrozil, clofibrate and fenofibrate, are another class of agents that are used as a second-line therapy for treatment of dyslipidaemia in patients with nephrotic syndrome. Their mechanism of action is to increase LPL activity, which decreases triglyceride synthesis and lowers serum triglyceride levels by 30-50\%. Fibrates have a much more modest effect on serum LDL levels than that induced by other agents, with typical reductions of approximately $10 \%^{112}$. Unfortunately, data describing the effectiveness of fibrates in patients with nephrotic syndrome are rather limited. A randomized, double-blind, placebo-controlled trial with a 6-week treatment with gemfibrozil showed a small reduction in cholesterol and LDL levels, and a marked reduction in triglyceride levels, in 11 patients with nephrotic syndrome ${ }^{134}$. Another small study of 12 paediatric patients with nephrotic syndrome who were randomly assigned to receive either gemfibrozil or placebo also showed lowering of serum cholesterol, LDL and triglyceride levels with gemfibrozil treatment ${ }^{135}$. However, a meta-analysis did not support the findings of that study ${ }^{131}$.

Nicotinic acid (also known as niacin) and ezetimibe are two additional agents that are used to treat hyperlipidaemia. Nicotonic acid inhibits diacylglycerol acyltransferase 2 in the liver, resulting in reduced triglyceride synthesis ${ }^{136}$, which in turn leads to decreased secretion of VLDL and LDL. In addition, nicotinic acid stimulates hepatic ApoA-I production, leading to increased HDL levels. Ezetimibe has a unique mechanism of action - it decreases enteric cholesterol absorption, resulting in markedly lower LDL cholesterol ${ }^{137}$. Ezetimibe is often a last-line agent for treatment of hyperlipidaemia in patients who are intolerant to statins, due to its limited vascular and clinical benefits ${ }^{138}$. However, neither nicotinic acid nor ezetimibe have been studied in patients with nephrotic syndrome.

Pharmacological treatments in children-In comparison to adults, the data describing the treatment of dyslipidaemia in paediatric patients with nephrotic syndrome are very limited. In fact, this dearth of data, together with the lack of FDA approval for use of lipidlowering agents in paediatric patients and a lack of long-term safety data, have led to a lower utilization of lipid-lowering agents in children with chronic nephrotic syndrome compared to adults. Most studies of paediatric patients have focused on statin therapy, with the exception of the above-described study of gemfibrozil ${ }^{135}$. One 12-month prospective, uncontrolled study of seven paediatric patients with nephrotic syndrome compared the use of dietary interventions before, or in combination with, simvastatin treatment ${ }^{139}$. This study reported a $30 \%$ reduction in cholesterol and a 36\% reduction in triglyceride levels from combination treatment. Another prospective, uncontrolled study of 12 paediatric patients with nephrotic syndrome who were treated with either lovastatin or simvastatin found decreases in cholesterol, LDL and triglyceride levels after 12 months of treatment with either $\operatorname{statin}^{140}$.

Lipid apheresis_Lipid apheresis is a novel treatment for dyslipidaemia in patients with nephrotic syndrome and is a well-established extracorporeal technique that is used to treat patients with homozygous familial hypercholesterolaemia. A study utilizing lipid apheresis in combination with prednisone in children with treatment-resistant nephrotic syndrome found reductions in both cholesterol and triglyceride levels ${ }^{141}$, similar to previous reports 
using lipid apheresis in adults ${ }^{142}$. However, the outcomes of this combination treatment in children with nephrotic syndrome were notable in that the majority of patients went into either complete or partial remission of their nephrotic syndrome ${ }^{141}$ — five of 11 patients (45\%) went into complete remission, and two of 11 patients (18\%) went into partial remission. Remarkably, all of the patients that responded to therapy remained in remission at 10 year follow-up. The mechanism by which lipid apheresis leads to remission remains unclear, but possible explanations include direct effects associated with improved dyslipidaemia, the removal of pathogenic vascular permeability factors and/or enhancement of the response to immunosuppressants ${ }^{62}$. One potential but unexplored hypothesis is that lipid apheresis, by lowering the level of free fatty acids, could reduce or prevent podocyte damage and reduce proteinuria ${ }^{99}$.

The prospective multicentre POLARIS trial in Japan assessed the efficacy of lipid apheresis for treating dyslipidaemia and inducing remission in patients with nephrotic syndrome. Initial results demonstrated nearly $50 \%$ reductions in both total cholesterol and LDL cholesterol levels during treatment ${ }^{143}$. A follow-up paper ${ }^{144}$ demonstrated complete remission in $25 \%$ of the 44 patients enrolled in the study, and reported that an additional $23 \%$ of patients had partial remission (defined as $<1 \mathrm{~g}$ of urinary protein per day).

Furthermore, a case report demonstrated the induction of remission by lipid apheresis in an adult with rituximab-resistant nephrotic syndrome ${ }^{145}$.

\section{Future treatment directions}

PCSK9 has a vital role in the regulation of cholesterol homeostasis and has thus gained considerable attention in the context of lipid-lowering strategies ${ }^{44}$. Furthermore, PCSK9 levels are elevated in patients with nephrotic syndrome, and are directly correlated with proteinuria $^{45-47}$. Of interest, remission in patients with nephrotic syndrome correlated with decreases in plasma levels of both cholesterol and PCSK9 (REF. 47). Inhibitors of PCSK9, in the form of monoclonal antibodies targeting PCSK9, have been developed as a new class of drug to treat dyslipidaemia, and have been shown to markedly lower LDL cholesterol levels when provided either as a monotherapy or in combination with statins ${ }^{44,45}$. PCSK9 promotes degradation of the LDL receptor in the liver, resulting in elevated LDL levels in the blood. However, the monoclonal anti-PCSK9 antibodies bind to and inactivate PCSK9, resulting in an increase in the level of LDL receptors on the surface of liver cells, thus promoting LDL uptake by the liver and its metabolism, which ultimately results in decreased LDL levels in the blood. A small inhibitory RNA (siRNA) inhibitor of PCSK9 has also been tested in a phase I trial to lower LDL cholesterol in healthy individuals (NCT02314442 (REF. 146)). The early results indicate that treatment with this siRNA had no serious adverse events, and induced significant reductions in the levels of PCSK9 and LDL cholesterol ${ }^{147}$.

Given their efficacy in treating dyslipidaemia and the potential link between an acquired LDL receptor deficiency and the pathogenesis of nephrotic syndrome ${ }^{148}$, future trials to explore the use of PCSK9 inhibitors in treating dyslipidaemia in patients with nephrotic syndrome are warranted. One such trial in adult patients with nephrotic syndrome, comparing the hypolipidaemic effects of statin monotherapy to those of a PCSK9 inhibitor in combination with a statin, is ongoing (NCT03004001 (REF. 149); TABLE 3). 
Interestingly, successful treatment of a patient with refractory nephrotic syndrome using a PCSK9 inhibitor has also been reported for the first time ${ }^{150}$. A practical obstacle in utilizing these agents is their tremendous cost, which is estimated at US $\$ 14,000$ per patient per year ${ }^{151}$.

Acetyl-CoA acetyltransferase (ACAT) inhibitors are another novel class of agents for the treatment of dyslipidaemia. Studies using low-dose therapy with ACAT inhibitors in animal models of nephrotic syndrome suggest that these inhibitors are also able to reduce proteinuria while improving dyslipidaemia ${ }^{152}$. However, enthusiasm for these agents has been tempered by a large randomized controlled trial of avasimibe, which did not demonstrate a favourable outcome in slowing coronary atherosclerosis ${ }^{153}$.

The high cost and the need in most cases for central venous access might limit the potential adoption of lipid apheresis. One system of lipid apheresis, the Liposorber LA-15 (Kaneka), is being utilized in a prospective study for the treatment of focal segmental glomerulosclerosis in children (NCT02235857 (REF. 154)). This study is a post-approval trial mandated by the FDA after the LA-15 system received a humanitarian device exemption for the treatment of paediatric patients with drug-resistant focal segmental glomerulosclerosis.

Despite the potential benefit of treating dyslipidaemia, it is important to note that no agreed criteria exist for a threshold of dyslipidaemia at which treatment should be initiated for patients with nephrotic syndrome. The Kidney Disease: Improving Global Outcomes guidelines for management of glomerular disease state "treatment of hyperlipidemia in patients with glomerular disease should usually follow the guidelines that apply to those at high risk for the development of cardiovascular disease." (REF. 155). No definitive data are available about when an intervention should take place. Instead, the potential benefits and risks of intervention or treatment of dyslipidaemia need to be considered on a case-by-case basis. Most nephrologists would consider the institution of lipid-lowering interventions in patients who remain overtly nephrotic for several months. Interestingly, one small study of 40 adult patients who had relapsing nephrotic syndrome as children showed that the occurrence of cardiovascular disease in this cohort was similar to that of the general population, suggesting that relapsing nephrotic syndrome during childhood does not portend an increased risk of cardiovascular disease as an adult ${ }^{156}$. As discussed above, although dietary interventions do not carry much risk, they also do not seem to be very effective in treating dyslipidaemia in patients with nephrotic syndrome. Statins have shown good efficacy in the treatment of other disease states, and are generally well tolerated in patients with nephrotic syndrome, but few, reliable outcome data exist for this patient population. Finally, although it is tempting to extrapolate findings from adults to children, it is important to note that very few data exist regarding the efficacy or, perhaps more importantly, the risks of pharmacological intervention among children with nephrotic syndrome.

\section{Conclusions}

The dyslipidaemia that accompanies nephrotic syndrome unfortunately remains one of the least understood yet most severe complications of nephrotic syndrome. Dyslipidaemia 
probably plays a part in the increased rate of atherosclerosis in patients with nephrotic syndrome, which in turn increases the risks of multiple cardiovascular morbidities, including stroke, myocardial infarction and thrombosis. More importantly, dyslipidaemia itself causes renal injury, which, if not interrupted, contributes to progressive CKD and, ultimately, the development of end-stage renal disease in some patients. Despite improved understanding of how nephrotic syndrome leads to altered lipid metabolism, including the origin of hypertriglyceridaemia and direct injury of podocytes, we still do not fully understand its molecular pathogenesis. In addition, many of the standard therapies for dyslipidaemia have not yet been studied in well-controlled trials of patients with nephrotic syndrome. This lack of clinical trials contributes to delays in the adoption of many newer therapies, including PCSK9 inhibitors, which, despite their cost, seem to be quite effective in other patient populations. Furthermore, many of these novel therapies, such as lipid apheresis using the Liposorber LA-15, if shown to be successful, could also enhance our understanding of the molecular pathogenesis of dyslipidaemia in patients with nephrotic syndrome.

\section{Acknowledgments}

The authors acknowledge the expert assistance of L. Feurer (Center for Clinical and Translational Research, The Research Institute at Nationwide Childrens Hospital, Columbus, Ohio, USA) in creating initial drafts of the figures in this manuscript.

\section{Glossary}

Sialylation

Glycocalyx,

Tangier disease

Lipid raft

Lipid apheresis
Addition of sialic acid groups onto molecules such as oligosaccharides and carbohydrates

Layer of glycoproteins and sugar moieties surrounding the outer surface of the cell membrane of some bacteria, epithelia and other cells

A rare inherited disorder characterized by significantly reduced levels of HDL in the blood

A subdomain of the plasma membrane that contain high concentrations of cholesterol and glycosphingolipids

A non-surgical therapy and a form of apheresis that removes LDL from a patient's blood

\section{References}

1. Greenbaum LA, Benndorf R, Smoyer WE. Childhood nephrotic syndrome - current and future therapies. Nat Rev Nephrol. 2012; 8:445-458. [PubMed: 22688744]

2. Hull RP, Goldsmith DJ. Nephrotic syndrome in adults. BMJ. 2008; 336:1185-1189. [PubMed: 18497417]

3. Clark, AG., Barratt, TM. Pediatric Nephrology. Barratt, TM.Avner, ED., Harmon, WE., editors. Lippincott Williams \& Wilkins; 1998. p. 731-747.

4. McEnery PT, Strife CF. Nephrotic syndrome in childhood. Management and treatment in patients with minimal change disease, mesangial proliferation, or focal glomerulosclerosis. Pediatr Clin North Am. 1982; 89:875-894. 
5. Nash, MA., Edelmann, CMJ., Bernstein, J., Barnett, HL. Pediatric Kidney Disease. Edelmann, CMJ., editor. Little; 1992. p. 1247-1266.

6. Ponticelli $\mathrm{C}$, et al. Can prolonged treatment improve the prognosis in adults with focal segmental glomerulosclerosis? Am J Kidney Dis. 1999; 34:618-625. [PubMed: 10516340]

7. MacHardy N, et al. Management patterns of childhood-onset nephrotic syndrome. Pediatr Nephrol. 2009; 24:2193-2201. [PubMed: 19672630]

8. Ding WY, Saleem MA. Current concepts of the podocyte in nephrotic syndrome. Kidney Res Clin Pract. 2012; 31:87-93. [PubMed: 26889414]

9. Harris RC, Ismail N. Extrarenal complications of the nephrotic syndrome. Am J Kidney Dis. 1994; 23:477-497. [PubMed: 8154483]

10. Cameron JS. The nephrotic syndrome and its complications. Am J Kidney Dis. 1987; 10:157-171. [PubMed: 3307394]

11. Llach F. Hypercoagulability, renal vein thrombosis, and other thrombotic complications of nephrotic syndrome. Kidney Int. 1985; 28:429-439. [PubMed: 3906225]

12. Rheault MN, et al. AKI in children hospitalized with nephrotic syndrome. Clin J Am Soc Nephrol. 2015; 10:2110-2118. [PubMed: 26450933]

13. Al-Azzawi HF, Obi OC, Safi J, Song M. Nephrotic syndrome-induced thromboembolism in adults. Int J Crit Illn Inj Sci. 2016; 6:85-88. [PubMed: 27308257]

14. Kerlin BA, Ayoob R, Smoyer WE. Epidemiology and pathophysiology of nephrotic syndromeassociated thromboembolic disease. Clin J Am Soc Nephrol. 2012; 7:513-520. [PubMed: 22344511]

15. Kerlin BA, Haworth K, Smoyer WE. Venous thromboembolism in pediatric nephrotic syndrome. Pediatr Nephrol. 2014; 29:989-997. [PubMed: 23812352]

16. Loscalzo J. Venous thrombosis in the nephrotic syndrome. N Engl J Med. 2013; 368:956-958. [PubMed: 23465106]

17. Vaziri ND. Disorders of lipid metabolism in nephrotic syndrome: mechanisms and consequences. Kidney Int. 2016; 90:41-52. [PubMed: 27165836]

18. Joven J, et al. Abnormalities of lipoprotein metabolism in patients with the nephrotic syndrome. $\mathrm{N}$ Engl J Med. 1990; 323:579-584. [PubMed: 2381443]

19. Zhou H, Tan KC, Shiu SW, Wong Y. Cellular cholesterol efflux to serum is impaired in diabetic nephropathy. Diabetes Metab Res Rev. 2008; 24:617-623. [PubMed: 18802933]

20. de Sain-van der Velden MG, et al. Increased VLDL in nephrotic patients results from a decreased catabolism while increased LDL results from increased synthesis. Kidney Int. 1998; 53:994-1001. [PubMed: 9551409]

21. Garber DW, Gottlieb BA, Marsh JB, Sparks CE. Catabolism of very low density lipoproteins in experimental nephrosis. J Clin Invest. 1984; 74:1375-1383. [PubMed: 6480830]

22. Davies RW, Staprans I, Hutchison FN, Kaysen GA. Proteinuria, not altered albumin metabolism, affects hyperlipidemia in the nephrotic rat. J Clin Invest. 1990; 86:600-605. [PubMed: 2384606]

23. Vaziri ND. Dyslipidemia of chronic renal failure: the nature, mechanisms, and potential consequences. Am J Physiol Renal Physiol. 2006; 290:F262-F272. [PubMed: 16403839]

24. Mace C, Chugh SS. Nephrotic syndrome: components, connections, and angiopoietin-like 4-related therapeutics. J Am Soc Nephrol. 2014; 25:2393-2398. [PubMed: 24854282]

25. Keith DS, Nichols GA, Gullion CM, Brown JB, Smith DH. Longitudinal follow-up and outcomes among a population with chronic kidney disease in a large managed care organization. Arch Intern Med. 2004; 164:659-663. [PubMed: 15037495]

26. Yeang C, Gordts PL, Tsimikas S. Novel lipoprotein(a) catabolism pathway via apolipoprotein(a) recycling: Adding the plasminogen receptor PlgRKT to the list. Circ Res. 2017; 120:1050-1052. [PubMed: 28360338]

27. Sharma M, Redpath GM, Williams MJ, McCormick SP. Recycling of apolipoprotein(a) after PlgRKT-mediated endocytosis of lipoprotein(a). Circ Res. 2017; 120:1091-1102. [PubMed: 28003220] 
28. Moriarty PM, Varvel SA, Gordts PL, McConnell JP, Tsimikas S. Lipoprotein(a) mass levels increase significantly according to APOE genotype: an analysis of 431239 patients. Arterioscler Thromb Vasc Biol. 2017; 37:580-588. [PubMed: 28062489]

29. Merkel M, Eckel RH, Goldberg IJ. Lipoprotein lipase: genetics, lipid uptake, and regulation. J Lipid Res. 2002; 43:1997-2006. [PubMed: 12454259]

30. Allan CM, et al. Mobility of "HSPG-bound" LPL explains how LPL is able to reach GPIHBP1 on capillaries. J Lipid Res. 2017; 58:216-225. [PubMed: 27811232]

31. Davies BS, et al. GPIHBP1 is responsible for the entry of lipoprotein lipase into capillaries. Cell Metab. 2010; 12:42-52. [PubMed: 20620994]

32. Vaziri ND, Yuan J, Ni Z, Nicholas SB, Norris KC. Lipoprotein lipase deficiency in chronic kidney disease is accompanied by down-regulation of endothelial GPIHBP1 expression. Clin Exp Nephrol. 2012; 16:238-243. [PubMed: 22009636]

33. Moorhead JF, Chan MK, El-Nahas M, Varghese Z. Lipid nephrotoxicity in chronic progressive glomerular and tubulo-interstitial disease. Lancet. 1982; 2:1309-1311. [PubMed: 6128601]

34. Clement LC, et al. Circulating angiopoietin-like 4 links proteinuria with hypertriglyceridemia in nephrotic syndrome. Nat Med. 2014; 20:37-46. [PubMed: 24317117]

35. Sukonina V, Lookene A, Olivecrona T, Olivecrona G. Angiopoietin-like protein 4 converts lipoprotein lipase to inactive monomers and modulates lipase activity in adipose tissue. Proc Natl Acad Sci USA. 2006; 103:17450-17455. [PubMed: 17088546]

36. Lafferty MJ, Bradford KC, Erie DA, Neher SB. Angiopoietin-like protein 4 inhibition of lipoprotein lipase: evidence for reversible complex formation. J Biol Chem. 2013; 288:2852428534. [PubMed: 23960078]

37. Liang K, Vaziri ND. Acquired VLDL receptor deficiency in experimental nephrosis. Kidney Int. 1997; 51:1761-1765. [PubMed: 9186864]

38. Zhou Y, et al. Expression profiling of hepatic genes associated with lipid metabolism in nephrotic rats. Am J Physiol Renal Physiol. 2008; 295:F662-F671. [PubMed: 18614621]

39. O’Donnell MP. Mechanisms and clinical importance of hypertriglyceridemia in the nephrotic syndrome. Kidney Int. 2001; 59:380-382. [PubMed: 11135095]

40. Kashyap ML, et al. Apolipoprotein CII and lipoprotein lipase in human nephrotic syndrome. Atherosclerosis. 1980; 35:29-40. [PubMed: 7370086]

41. Ohta T, Matsuda I. Lipid and apolipoprotein levels in patients with nephrotic syndrome. Clin Chim Acta. 1981; 117:133-143. [PubMed: 6796292]

42. Nasr SH, et al. Novel type of renal amyloidosis derived from apolipoprotein-CII. J Am Soc Nephrol. 2017; 28:439-445. [PubMed: 27297947]

43. Tentolouris $\mathrm{N}$, et al. High postprandial triglyceridemia in patients with type 2 diabetes and microalbuminuria. J Lipid Res. 2007; 48:218-225. [PubMed: 17018886]

44. Di Bartolo B, Scherer DJ, Brown A, Psaltis PJ, Nicholls SJ. PCSK9 inhibitors in hyperlipidemia: current status and clinical outlook. BioDrugs. 2017; 31:167-174. [PubMed: 28424973]

45. Morris AW. Nephrotic syndrome: PCSK9: a target for hypercholesterolaemia in nephrotic syndrome. Nat Rev Nephrol. 2016; 12:510. [PubMed: 27425160]

46. Pavlakou P, Liberopoulos E, Dounousi E, Elisaf M. PCSK9 in chronic kidney disease. Int Urol Nephrol. 2017; 49:1015-1024. [PubMed: 28084558]

47. Haas ME, et al. The role of proprotein convertase subtilisin/kexin type 9 in nephrotic syndromeassociated hypercholesterolemia. Circulation. 2016; 134:61-72. [PubMed: 27358438]

48. Warwick GL, et al. Low-density lipoprotein metabolism in the nephrotic syndrome. Metabolism. 1990; 39:187-192. [PubMed: 2299990]

49. Vaziri ND, Liang KH. Hepatic HMG-CoA reductase gene expression during the course of puromycin-induced nephrosis. Kidney Int. 1995; 48:1979-1985. [PubMed: 8587261]

50. Tsimikas S, et al. Oxidized phospholipids, Lp(a) lipoprotein, and coronary artery disease. N Engl J Med. 2005; 353:46-57. [PubMed: 16000355]

51. Wanner C, et al. Elevated plasma lipoprotein(a) in patients with the nephrotic syndrome. Ann Intern Med. 1993; 119:263-269. [PubMed: 8328733] 
52. Glass CK, Witztum JL. Atherosclerosis: the road ahead. Cell. 2001; 104:503-516. [PubMed: 11239408]

53. Gherardi E, Rota E, Calandra S, Genova R, Tamborino A. Relationship among the concentrations of serum lipoproteins and changes in their chemical composition in patients with untreated nephrotic syndrome. Eur J Clin Invest. 1977; 7:563-570. [PubMed: 415877]

54. Yvan-Charvet L, Wang N, Tall AR. Role of HDL, ABCA1, and ABCG1 transporters in cholesterol efflux and immune responses. Arterioscler Thromb Vasc Biol. 2010; 30:139-143. [PubMed: 19797709]

55. Birjmohun RS, et al. High-density lipoprotein attenuates inflammation and coagulation response on endotoxin challenge in humans. Arterioscler Thromb Vasc Biol. 2007; 27:1153-1158. [PubMed: 17303780]

56. Murphy AJ, et al. High-density lipoprotein reduces the human monocyte inflammatory response. Arterioscler Thromb Vasc Biol. 2008; 28:2071-2077. [PubMed: 18617650]

57. Yuhanna IS, et al. High-density lipoprotein binding to scavenger receptor-BI activates endothelial nitric oxide synthase. Nat Med. 2001; 7:853-857. [PubMed: 11433352]

58. Muls E, Rosseneu M, Daneels R, Schurgers M, Boelaert J. Lipoprotein distribution and composition in the human nephrotic syndrome. Atherosclerosis. 1985; 54:225-237. [PubMed: 3986019]

59. Vaziri ND. HDL abnormalities in nephrotic syndrome and chronic kidney disease. Nat Rev Nephrol. 2016; 12:37-47. [PubMed: 26568191]

60. Pedigo CE, et al. Local TNF causes NFATc1-dependent cholesterol-mediated podocyte injury. J Clin Invest. 2016; 126:3336-3350. [PubMed: 27482889]

61. Jao W, Lewy P, Norris SH, Pollak VE, Pirani CL. Lipoid nephrosis: a reassessment. Perspect Nephrol Hypertens. 1973; 1:183-198. [PubMed: 4620918]

62. Muso E. Beneficial effect of LDL-apheresis in refractory nephrotic syndrome. Clin Exp Nephrol. 2014; 18:286-290. [PubMed: 24535024]

63. Gordon T, Castelli WP, Hjortland MC, Kannel WB, Dawber TR. High density lipoprotein as a protective factor against coronary heart disease: the Framingham study. Am J Med. 1977; 62:707714. [PubMed: 193398]

64. Rye KA, Barter PJ. Cardioprotective functions of HDLs. J Lipid Res. 2014z; 55:168-179. [PubMed: 23812558]

65. Boden WE, et al. Niacin in patients with low HDL cholesterol levels receiving intensive statin therapy. N Engl J Med. 2011; 365:2255-2267. [PubMed: 22085343]

66. Barter PJ, et al. Effects of torcetrapib in patients at high risk for coronary events. N Engl J Med. 2007; 357:2109-2122. [PubMed: 17984165]

67. Brunzell JD, Zambon A, Deeb SS. The effect of hepatic lipase on coronary artery disease in humans is influenced by the underlying lipoprotein phenotype. Biochim Biophys Acta. 2012; 1821:365-372. [PubMed: 21986251]

68. Voight BF, et al. Plasma HDL cholesterol and risk of myocardial infarction: a mendelian randomisation study. Lancet. 2012; 380:572-580. [PubMed: 22607825]

69. US National Library of Medicine. ClinicalTrials.gov. 2015. https://clinicaltrials.gov/ct2/show/ NCT01841684

70. Brooks, M. REVEAL: CETP inhibitor anacetrapib meets primary end point. Medscape Nephrology. 2017. http://www.medscape.com/viewarticle/882173

71. Faraggiana T, Churg J. Renal lipidoses: a review. Hum Pathol. 1987; 18:661-679. [PubMed: 3297993]

72. Ossoli A, et al. Lipoprotein X causes renal disease in LCAT deficiency. PLoS ONE. 2016; 11:e0150083. [PubMed: 26919698]

73. Ferrans VJ, Fredrickson DS. The pathology of Tangier disease. A light and electron microscopic study. Am J Pathol. 1975; 78:101-158. [PubMed: 162820]

74. Lovric S, et al. Mutations in sphingosine-1-phosphate lyase cause nephrosis with ichthyosis and adrenal insufficiency. J Clin Invest. 2017; 127:912-928. [PubMed: 28165339] 
75. Fornoni A, et al. Rituximab targets podocytes in recurrent focal segmental glomerulosclerosis. Sci Transl Med. 2011; 3:85ra46.

76. Choi HK, Seeger JD. Glucocorticoid use and serum lipid levels in US adults: the Third National Health and Nutrition Examination Survey. Arthritis Rheum. 2005; 53:528-535. [PubMed: 16082633]

77. Leong KH, Koh ET, Feng PH, Boey ML. Lipid profiles in patients with systemic lupus erythematosus. J Rheumatol. 1994; 21:1264-1267. [PubMed: 7966068]

78. MacGregor AJ, et al. Fasting lipids and anticardiolipin antibodies as risk factors for vascular disease in systemic lupus erythematosus. Ann Rheum Dis. 1992; 51:152-155. [PubMed: 1550394]

79. Macfarlane DP, Forbes S, Walker BR. Glucocorticoids and fatty acid metabolism in humans: fuelling fat redistribution in the metabolic syndrome. J Endocrinol. 2008; 197:189-204. [PubMed: 18434349]

80. Vincenti F, Jensik SC, Filo RS, Miller J, Pirsch J. A long-term comparison of tacrolimus (FK506) and cyclosporine in kidney transplantation: evidence for improved allograft survival at five years. Transplantation. 2002; 73:775-782. [PubMed: 11907427]

81. Mayer AD, et al. Multicenter randomized trial comparing tacrolimus (FK506) and cyclosporine in the prevention of renal allograft rejection: a report of the European Tacrolimus Multicenter Renal Study Group. Transplantation. 1997; 64:436-443. [PubMed: 9275110]

82. Jackson SP, Calkin AC. The clot thickens — oxidized lipids and thrombosis. Nat Med. 2007; 13:1015-1016. [PubMed: 17828215]

83. Podrez EA, et al. Platelet CD36 links hyperlipidemia, oxidant stress and a prothrombotic phenotype. Nat Med. 2007; 13:1086-1095. [PubMed: 17721545]

84. Gyebi L, Soltani Z, Reisin E. Lipid nephrotoxicity: new concept for an old disease. Curr Hypertens Rep. 2012; 14:177-181. [PubMed: 22290079]

85. Thomas ME, Harris KP, Walls J, Furness PN, Brunskill NJ. Fatty acids exacerbate tubulointerstitial injury in protein-overload proteinuria. Am J Physiol Renal Physiol. 2002; 283:F640-F647. [PubMed: 12217854]

86. Kamijo A, et al. Urinary free fatty acids bound to albumin aggravate tubulointerstitial damage. Kidney Int. 2002; 62:1628-1637. [PubMed: 12371963]

87. Schermer B, Benzing T. Lipid-protein interactions along the slit diaphragm of podocytes. J Am Soc Nephrol. 2009; 20:473-478. [PubMed: 19244577]

88. Schlondorff D. Cellular mechanisms of lipid injury in the glomerulus. Am J Kidney Dis. 1993; 22:72-82. [PubMed: 8322798]

89. Nishida Y, Oda H, Yorioka N. Effect of lipoproteins on mesangial cell proliferation. Kidney Int Suppl. 1999; 71:S51-S53. [PubMed: 10412737]

90. Stevenson FT, Shearer GC, Atkinson DN. Lipoprotein-stimulated mesangial cell proliferation and gene expression are regulated by lipoprotein lipase. Kidney Int. 2001; 59:2062-2068. [PubMed: 11380807]

91. Shearer GC, et al. Hypoalbuminemia and proteinuria contribute separately to reduced lipoprotein catabolism in the nephrotic syndrome. Kidney Int. 2001; 59:179-189. [PubMed: 11135070]

92. Zhong S, et al. Inflammatory stress exacerbated mesangial foam cell formation and renal injury via disrupting cellular cholesterol homeostasis. Inflammation. 2015; 38:959-971. [PubMed: 25387652]

93. Kopp JB, et al. APOL1 genetic variants in focal segmental glomerulosclerosis and HIV-associated nephropathy. J Am Soc Nephrol. 2011; 22:2129-2137. [PubMed: 21997394]

94. Genovese G, et al. Association of trypanolytic ApoL1 variants with kidney disease in African Americans. Science. 2010; 329:841-845. [PubMed: 20647424]

95. Freedman BI, et al. The apolipoprotein L1 (APOL1) gene and nondiabetic nephropathy in African Americans. J Am Soc Nephrol. 2010; 21:1422-1426. [PubMed: 20688934]

96. Debiec H, Ronco P. PLA2R autoantibodies and PLA2R glomerular deposits in membranous nephropathy. N Engl J Med. 2011; 364:689-690. [PubMed: 21323563]

97. Beck LH Jr , et al. M-Type phospholipase A2 receptor as target antigen in idiopathic membranous nephropathy. N Engl J Med. 2009; 361:11-21. [PubMed: 19571279] 
98. Fornoni A, Merscher S, Kopp JB. Lipid biology of the podocyte - new perspectives offer new opportunities. Nat Rev Nephrol. 2014; 10:379-388. [PubMed: 24861084]

99. Chung JJ, et al. Albumin-associated free fatty acids induce macropinocytosis in podocytes. J Clin Invest. 2015; 125:2307-2316. [PubMed: 25915582]

100. Allison SJ. Free fatty acid-induced macropinocytosis in podocytes. Nat Rev Nephrol. 2015; 11:386. [PubMed: 25963589]

101. Agrawal S, Guess AJ, Chanley MA, Smoyer WE. Albumin-induced podocyte injury and protection are associated with regulation of COX-2. Kidney Int. 2014; 86:1150-1160. [PubMed: 24918154]

102. Sieber J, et al. Regulation of podocyte survival and endoplasmic reticulum stress by fatty acids. Am J Physiol Renal Physiol. 2010; 299:F821-F829. [PubMed: 20668104]

103. Kampe K, Sieber J, Orellana JM, Mundel P, Jehle AW. Susceptibility of podocytes to palmitic acid is regulated by fatty acid oxidation and inversely depends on acetyl-CoA carboxylases 1 and 2. Am J Physiol Renal Physiol. 2014; 306:F401-F409. [PubMed: 24338821]

104. Martinez-Garcia C, et al. Renal lipotoxicity-associated inflammation and insulin resistance affects actin cytoskeleton organization in podocytes. PLoS ONE. 2015; 10:e0142291. [PubMed: 26545114]

105. Eddy AA, Michael AF. Acute tubulointerstitial nephritis associated with aminonucleoside nephrosis. Kidney Int. 1988; 33:14-23. [PubMed: 3258389]

106. Eddy AA, McCulloch L, Liu E, Adams J. A relationship between proteinuria and acute tubulointerstitial disease in rats with experimental nephrotic syndrome. Am J Pathol. 1991; 138:1111-1123. [PubMed: 2024704]

107. Iwai T, et al. Stearoyl-CoA desaturase-1 protects cells against lipotoxicity-mediated apoptosis in proximal tubular cells. Int J Mol Sci. 2016; 17:E1868. [PubMed: 27834856]

108. Li C, et al. Intrarenal renin-angiotensin system mediates fatty acid-induced ER stress in the kidney. Am J Physiol Renal Physiol. 2016; 310:F351-F363. [PubMed: 26672616]

109. Zuo N, Zheng X, Liu H, Ma X. Fenofibrate, a PPARa agonist, protect proximal tubular cells from albumin-bound fatty acids induced apoptosis via the activation of NF-kB. Int J Clin Exp Pathol. 2015; 8:10653-10661. [PubMed: 26617775]

110. Ruggiero C, et al. Albumin-bound fatty acids but not albumin itself alter redox balance in tubular epithelial cells and induce a peroxide-mediated redox-sensitive apoptosis. Am J Physiol Renal Physiol. 2014; 306:F896-F906. [PubMed: 24500687]

111. Sacks FM, et al. The effect of pravastatin on coronary events after myocardial infarction in patients with average cholesterol levels. N Engl J Med. 1996; 335:1001-1009. [PubMed: 8801446]

112. Reiner Z, et al. ESC/EAS Guidelines for the management of dyslipidaemias: the Task Force for the management of dyslipidaemias of the European Society of Cardiology (ESC) and the European Atherosclerosis Society (EAS). Eur Heart J. 2011; 32:1769-1818. [PubMed: 21712404]

113. Bagga A, Sharma A, Srivastava RN. Inefficacy of pefloxacin in steroid-responsive nephrotic syndrome. Pediatr Nephrol. 1995; 9:793-794. [PubMed: 8747133]

114. Keane WF. Lipids and the kidney. Kidney Int. 1994; 46:910-920. [PubMed: 7996813]

115. Culleton BF, et al. Cardiovascular disease and mortality in a community-based cohort with mild renal insufficiency. Kidney Int. 1999; 56:2214-2219. [PubMed: 10594797]

116. Falk, RJ. Acute Renal Failure: A Companion to Brenner \& Rector's The Kidney. Molitoris, BA., Finn, W., editors. Saunders; 2001.

117. Kasiske BL. Hyperlipidemia in patients with chronic renal disease. Am J Kidney Dis. 1998; 32:S142-S156.

118. Ordonez JD, Hiatt RA, Killebrew EJ, Fireman BH. The increased risk of coronary heart disease associated with nephrotic syndrome. Kidney Int. 1993; 44:638-642. [PubMed: 8231039]

119. Suryawanshi SP, Das B, Patnaik AN. Myocardial infarction in children: two interesting cases. Ann Pediatr Cardiol. 2011; 4:81-83. [PubMed: 21677815] 
120. Silva JM, et al. Premature acute myocardial infarction in a child with nephrotic syndrome. Pediatr Nephrol. 2002; 17:169-172. [PubMed: 11956853]

121. D'Amico G, et al. Effect of vegetarian soy diet on hyperlipidaemia in nephrotic syndrome. Lancet. 1992; 339:1131-1134. [PubMed: 1349366]

122. Gentile MG, et al. Treatment of proteinuric patients with a vegetarian soy diet and fish oil. Clin Nephrol. 1993; 40:315-320. [PubMed: 8299238]

123. Bell S, Cooney J, Packard CJ, Caslake MJ, Deighan CJ. The effect of omega-3 fatty acids on the atherogenic lipoprotein phenotype in patients with nephrotic range proteinuria. Clin Nephrol. 2012; 77:445-453. [PubMed: 22595386]

124. Hall AV, et al. Omega-3 fatty acid supplementation in primary nephrotic syndrome: effects on plasma lipids and coagulopathy. J Am Soc Nephrol. 1992; 3:1321-1329. [PubMed: 1477328]

125. Rabelink AJ, Hene RJ, Erkelens DW, Joles JA, Koomans HA. Effects of simvastatin and cholestyramine on lipoprotein profile in hyperlipidaemia of nephrotic syndrome. Lancet. 1988; 2:1335-1338. [PubMed: 2904053]

126. Thomas ME, et al. Simvastatin therapy for hypercholesterolemic patients with nephrotic syndrome or significant proteinuria. Kidney Int. 1993; 44:1124-1129. [PubMed: 8264145]

127. MS, et al. Evaluation of effects of lovastatin on hyercholesterolaemia and renl functions in nephrotic syndrome. Indian Acad Clin Med. 2004; 5:143-146.

128. Gheith OA, et al. Impact of treatment of dyslipidemia on renal function, fat deposits and scarring in patients with persistent nephrotic syndrome. Nephron. 2002; 91:612-619. [PubMed: 12138263]

129. Gheith O, Sheashaa H, Abdelsalam M, Shoeir Z, Sobh M. Efficacy and safety of Monascus purpureus Went rice in subjects with secondary hyperlipidemia. Clin Exp Nephrol. 2008; 12:189-194. [PubMed: 18363032]

130. Olbricht CJ, Wanner C, Thiery J, Basten A. Simvastatin in nephrotic syndrome. Kidney Int Suppl. 1999; 71:S113-S116. [PubMed: 10412752]

131. Kong X, et al. Lipid-lowering agents for nephrotic syndrome. Cochrane Database Syst Rev. 2013; 12:CD005425.

132. Baigent C, et al. The effects of lowering LDL cholesterol with simvastatin plus ezetimibe in patients with chronic kidney disease (Study of Heart and Renal Protection): a randomised placebo-controlled trial. Lancet. 2011; 377:2181-2192. [PubMed: 21663949]

133. Valeri A, Gelfand J, Blum C, Appel GB. Treatment of the hyperlipidemia of the nephrotic syndrome: a controlled trial. Am J Kidney Dis. 1986; 8:388-396. [PubMed: 3544820]

134. Groggel GC, Cheung AK, Ellis-Benigni K, Wilson DE. Treatment of nephrotic hyperlipoproteinemia with gemfibrozil. Kidney Int. 1989; 36:266-271. [PubMed: 2779095]

135. Buyukcelik M, et al. The effects of gemfibrozil on hyperlipidemia in children with persistent nephrotic syndrome. Turk J Pediatr. 2002; 44:40-44. [PubMed: 11858378]

136. Kamanna VS, Kashyap ML. Mechanism of action of niacin. Am J Cardiol. 2008; 101:20B-26B. [PubMed: 18157959]

137. Phan BA, Dayspring TD, Toth PP. Ezetimibe therapy: mechanism of action and clinical update. Vasc Health Risk Manag. 2012; 8:415-427. [PubMed: 22910633]

138. Kastelein JJ, et al. Simvastatin with or without ezetimibe in familial hypercholesterolemia. N Engl J Med. 2008; 358:1431-1443. [PubMed: 18376000]

139. Coleman JE, Watson AR. Hyperlipidaemia, diet and simvastatin therapy in steroid-resistant nephrotic syndrome of childhood. Pediatr Nephrol. 1996; 10:171-174. [PubMed: 8703704]

140. Sanjad SA, al-Abbad A, al-Shorafa S. Management of hyperlipidemia in children with refractory nephrotic syndrome: the effect of statin therapy. J Pediatr. 1997; 130:470-474. [PubMed: 9063427]

141. Hattori M, et al. A combined low-density lipoprotein apheresis and prednisone therapy for steroid-resistant primary focal segmental glomerulosclerosis in children. Am J Kidney Dis. 2003; 42:1121-1130. [PubMed: 14655182] 
142. Muso E, et al. Low density lipoprotein apheresis therapy for steroid-resistant nephrotic syndrome. Kansai-FGS-Apheresis Treatment (K-FLAT) Study Group. Kidney Int Suppl. 1999; 71:S122S125. [PubMed: 10412754]

143. Muso E, et al. Immediate therapeutic efficacy of low-density lipoprotein apheresis for drugresistant nephrotic syndrome: evidence from the short-term results from the POLARIS Study. Clin Exp Nephrol. 2015; 19:379-386. [PubMed: 24934117]

144. Muso E, et al. A prospective observational survey on the long-term effect of LDL apheresis on drug-resistant nephrotic syndrome. Nephron Extra. 2015; 5:58-66. [PubMed: 26557843]

145. Suzuki H, Tsukamoto T, Muso E. Rituximab-resistant nephrotic syndrome with successful induction of remission by low-density lipoprotein apheresis. Ther Apher Dial. 2017; 21:295-296. [PubMed: 28661090]

146. US National Library of Medicine. ClinicalTrials.gov. 2015. https://clinicaltrials.gov/ct2/show/ NCT02314442

147. Fitzgerald K, et al. A highly durable RNAi therapeutic inhibitor of PCSK9. N Engl J Med. 2017; 376:41-51. [PubMed: 27959715]

148. Liu S, Vaziri ND. Role of PCSK9 and IDOL in the pathogenesis of acquired LDL receptor deficiency and hypercholesterolemia in nephrotic syndrome. Nephrol Dial Transplant. 2014; 29:538-543. [PubMed: 24166456]

149. US National Library of Medicine. ClinicalTrials.gov. 2017. https://clinicaltrials.gov/ct2/show/ NCT03004001

150. Awanami Y, et al. Successful treatment of a patient with refractory nephrotic syndrome with PCSK9 inhibitors: a case report. BMC Nephrol. 2017; 18:221. [PubMed: 28683788]

151. Kazi DS, et al. Cost-effectiveness of PCSK9 inhibitor therapy in patients with heterozygous familial hypercholesterolemia or atherosclerotic cardiovascular disease. JAMA. 2016; 316:743753. [PubMed: 27533159]

152. Vaziri ND, Liang KH. Acyl-coenzyme A:cholesterol acyltransferase inhibition ameliorates proteinuria, hyperlipidemia, lecithin-cholesterol acyltransferase, SRB-1, and low-denisty lipoprotein receptor deficiencies in nephrotic syndrome. Circulation. 2004; 110:419-425. [PubMed: 15262831]

153. Tardif JC, et al. Effects of the acyl coenzyme A: cholesterol acyltransferase inhibitor avasimibe on human atherosclerotic lesions. Circulation. 2004; 110:3372-3377. [PubMed: 15533865]

154. US National Library of Medicine. ClinicalTrials.gov. 2016. https://clinicaltrials.gov/ct2/show/ NCT02235857

155. Chapter 2: General principles in the management of glomerular disease. Kidney Int Suppl. 2012; 2:156-162. [No authors listed.].

156. Lechner BL, Bockenhauer D, Iragorri S, Kennedy TL, Siegel NJ. The risk of cardiovascular disease in adults who have had childhood nephrotic syndrome. Pediatr Nephrol. 2004; 19:744748. [PubMed: 15085419]

157. US National Library of Medicine. ClinicalTrials.gov. 2017. https://clinicaltrials.gov/ct2/show/ NCT00004466

158. US National Library of Medicine. ClinicalTrials.gov. 2017. https://clinicaltrials.gov/ct2/show/ NCT01845428 


\section{Key points}

- Prolonged hyperlipidaemia in nephrotic syndrome is a major risk factor for multiple disease complications, including accelerated atherosclerosis, myocardial infarction, stroke, chronic kidney disease and thrombosis

- Direct lipid-induced cellular injury to podocytes, mesangial cells and, potentially, renal tubular cells as a result of dyslipidaemia increasingly seems to have a role in the pathogenesis of nephrotic syndrome

- Given the available evidence, we suggest that statins should be the first-line treatment for prolonged hyperlipidaemia in patients with nephrotic syndrome, given their efficacy in the treatment of other diseases and the fact that they are well tolerated

- $\quad$ Alternative, less supported treatments include LDL apheresis, cholesterol absorption inhibitors, nicotinic acid and bile acid sequestrants; targeting proprotein convertase subtilisin/kexin type 9 is another potential treatment for hyperlipidaemia in patients with nephrotic syndrome

- Treatment recommendations in children are limited by a lack of data for both the efficacy and the risk of pharmacological interventions 


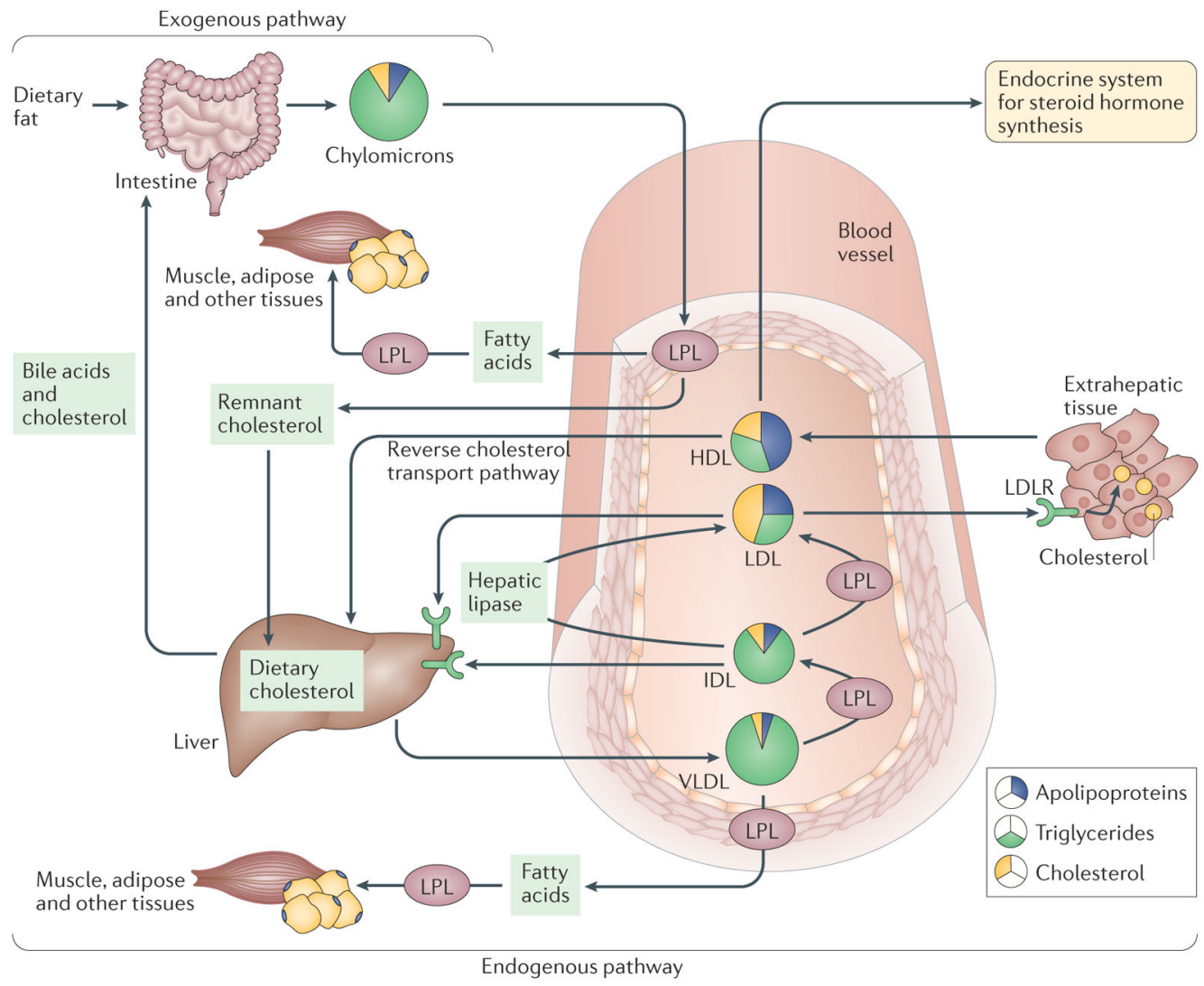

Figure 1. The major pathways of lipid metabolism

Lipoproteins are the major carriers of lipids in the circulation and they participate in three major pathways that are responsible for the generation and transport of lipids within the body. The two major forms of circulating lipid in the body, triglycerides and cholesterol, are packaged with apolipoproteins and phospholipids to form lipoproteins. The major forms of lipoproteins are chylomicrons, very low-density lipoprotein (VLDL), intermediate density lipoprotein (IDL), low density lipoprotein (LDL) and high density lipoprotein (HDL), and they differ in their size, density, composition and functions (detailed in TABLE 1). In the exogenous pathway, dietary lipids, which consist mainly of triglycerides (95\%) and some phospholipids, free fatty acids and cholesterol, are packaged into chylomicrons by intestinal mucosal cells. These chylomicrons enter the lymphatic system and then the circulation, where triglycerides are released as free fatty acids by lipoprotein lipase (LPL) activity on the capillary endothelium. These free fatty acids are taken up by the muscle, adipose and other peripheral tissues, whereas the remnants of chylomicrons are cleared by the liver. In the endogenous pathway, the liver produces VLDL, which interacts with LPL in the circulation to form IDL, with the release of triglyceride and free fatty acids. IDL is rapidly removed by the liver via the interaction of its apolipoprotein E component with LDL receptor (LDLR). Furthermore, IDL forms LDL upon removal of triglyceride by hepatic lipase. LDL, which is very high in cholesterol content, is in turn removed from the circulation by binding to LDLR in the liver and in extrahepatic tissues. HDL is an anti-atherogenic lipoprotein or 'good cholesterol', as it captures the cholesterol from peripheral tissues or other lipoproteins and transports it back to liver by the third pathway, which is termed reverse cholesterol transport. 


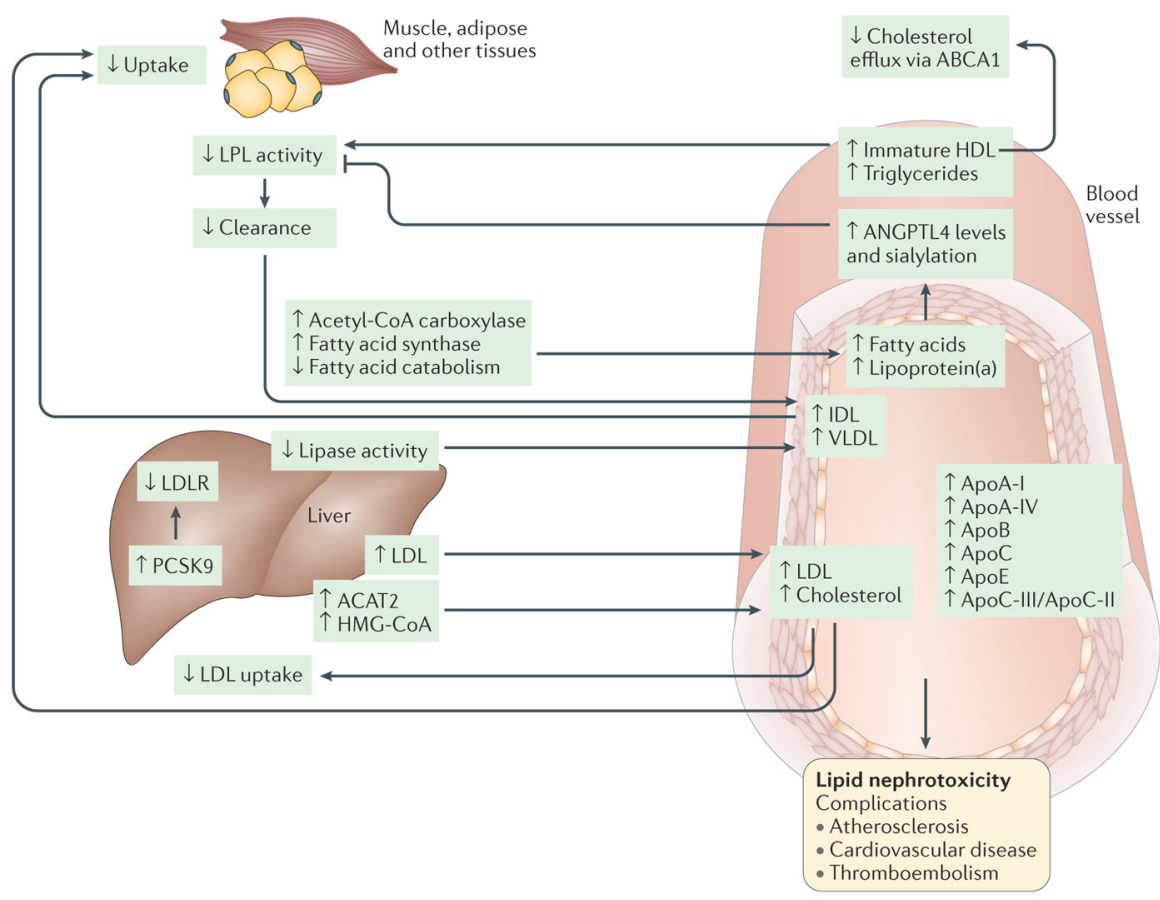

Figure 2. Pathophysiology of dyslipidaemia in nephrotic syndrome

Alterations of lipid and lipoprotein metabolism in nephrotic syndrome result in 'lipid nephrotoxicity' and other complications, such as atherosclerosis, cardiovascular disease and thromboembolism. The major lipoproteins, including intermediate density lipoprotein (IDL), very low density lipoprotein (VLDL) and low-density lipoprotein (LDL), and cholesterol are increased in the plasma of patients with nephrotic syndrome, owing mainly to impaired clearance and, to a lesser extent, increased biosynthesis. Impaired clearance is a direct result of decreased hepatic lipase activity and decreased lipoprotein lipase (LPL) activity in the endothelium and peripheral tissues, such as muscle and adipose. In addition, hepatic levels of proprotein convertase subtilisin/kexin type 9 (PCSK9) are increased in patients with nephrotic syndrome; PCSK9 degrades the LDL receptor (LDLR), and is thus a major therapeutic target for lipid lowering. Furthermore, the composition and function of the lipoproteins are also altered, with substantial increases in the plasma levels of apolipoprotein A I (ApoA I), ApoA IV, ApoB, ApoC and ApoE, and in the ApoC III/ApoC II ratio. The level of immature HDL in the plasma is also increased, resulting in reduced cholesterol efflux, which occurs mainly via ATP binding cassette subfamily A member 1 (ABCA1), in peripheral organs, including in podocytes. Another major lipid abnormality in nephrotic syndrome is hypertriglyceridaemia, as well as increased production and sialylation of ANGPTL4, which is driven primarily by increased circulating free fatty acids. ANGPTL4 in turn suppresses LPL activity by either preventing its dimerization or by inhibiting its activity noncompetitively. Hypercholesterolaemia and increased LDL levels occur in conjunction with upregulation of the expression and activity of liver acetyl CoA acetyltransferase 2 (ACAT2), which results in enhanced esterification of cholesterol and a reduction in the level of intracellular free cholesterol. Cholesterol synthesis via 3 hydroxy 3 methylglutaryl CoA (HMG CoA) reductase is also increased in experimental models of nephrotic syndrome. Evidence also exists that LDL oxidation in nephrotic syndrome may be augmented by 
lipoprotein(a), the level of which is also increased in patients with nephrotic syndrome. Accumulation of oxidized LDL, IDL and chylomicron remnants stimulates monocytes and macrophages to release proin ammatory cytokines and chemokines, and accelerates in ammation, which may in turn promote the progression of chronic kidney disease. 


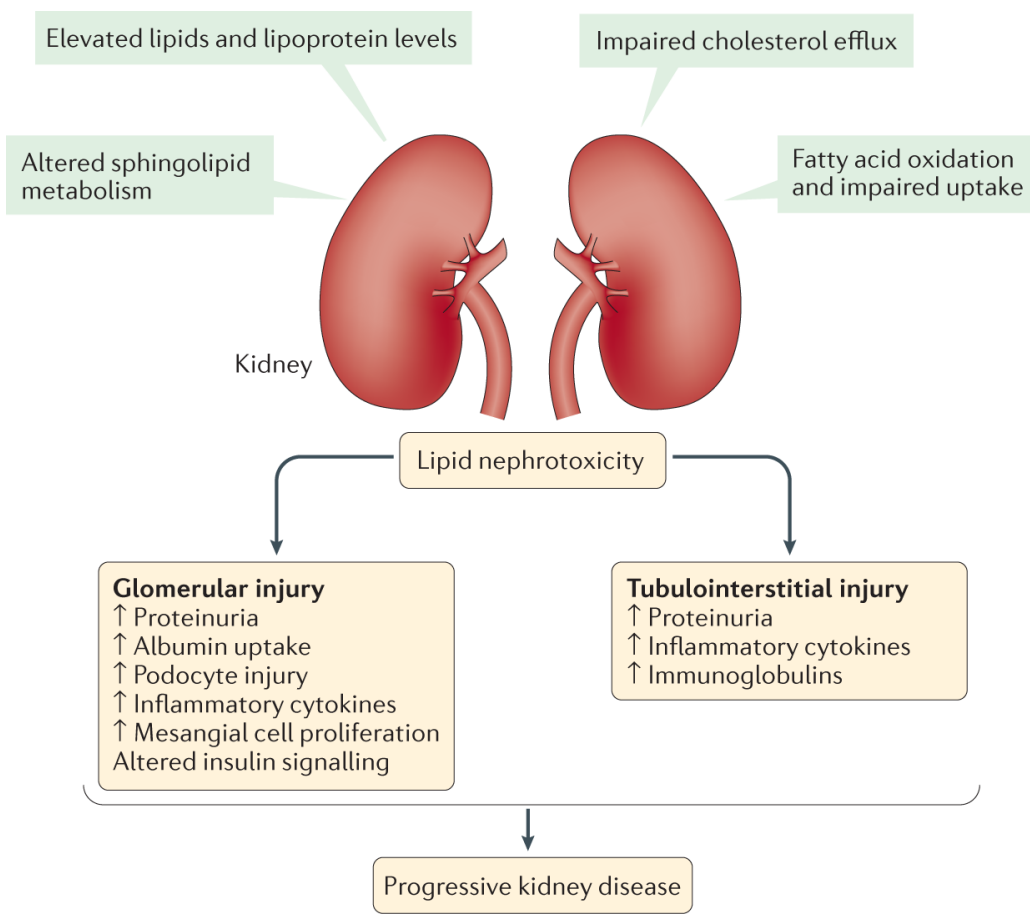

Figure 3. Mechanisms and consequences of lipid nephrotoxicity

The direct effects of dyslipidaemia on decreased kidney function are referred to as 'lipid nephrotoxicity', although the role of altered lipid metabolism in the molecular pathophysiology of nephrotic syndrome is not well understood. During dyslipidaemia, triglyceride-rich lipoproteins, such as very low density lipoprotein (VLDL) and intermediate density lipoprotein (IDL) as well as oxidized LDL, are taken up by mesangial cells, leading to the production of cytotoxic agents, cytokines and reactive oxygen species, which further damage the glomerular epithelial and endothelial cells, resulting in sclerosis. Furthermore, levels of free fatty acids are increased in patients with nephrotic syndrome, which have been reported to have toxic effects in the kidney, especially in glomeruli and podocytes, but also in the tubulointerstitium. Free fatty acids bound to albumin cause podocyte damage by enhancing macropinocytosis and activating G protein-coupled receptor (GPCR) signalling, leading to disruption of the podocyte actin cytoskeleton and podocyte morphology. In addition, these albumin bound free fatty acids cause loss of podocyte viability and increased production of several cytokines. Moreover, free cholesterol-mediated injury is another pathway of cellular injury in podocytes, and involves the ATP binding cassette sub family A member 1 (ABCA1) cholesterol transporter. Furthermore, the role of free fatty acids, and saturated fatty acids in particular, is well documented in causing damage to proximal tubule cells and tubulointerstitial injury. 


\section{Table 1}

\section{Classes of lipoproteins}

\begin{tabular}{|llll|}
\hline Lipoprotein & Composition & Apolipoproteins and enzymes & Function in normal physiology \\
\hline High-density lipoprotein (HDL) & $\begin{array}{l}\text { • Apolipoproteins (45\%) } \\
\text { • Cholesterol (25\%) } \\
\bullet \text { Triglycerides (30\%) }\end{array}$ & $\begin{array}{l}\text { • ApoA I, ApoA II, ApoC II, ApoC } \\
\text { III, ApoE, ApoL I }\end{array}$ & $\begin{array}{l}\text { Reverse cholesterol transport } \\
\text { from tissues to the liver }\end{array}$ \\
\hline Low-density lipoprotein (LDL) & $\begin{array}{l}\text { • Apolipoproteins (25\%) } \\
\text { - Cholesterol (45\%) } \\
\text { • Triglycerides (30\%) }\end{array}$ & ApoB-100 & Major cholesterol carrier \\
\hline $\begin{array}{l}\text { Intermediate density lipoprotein } \\
\text { (IDL) }\end{array}$ & $\begin{array}{l}\text { Mostly triglycerides and } \\
\text { some cholesterol }\end{array}$ & ApoB-100 & $\begin{array}{l}\text { Intermediate between LDL and } \\
\text { VLDL }\end{array}$ \\
\hline $\begin{array}{l}\text { Very low-density lipoprotein } \\
\text { (VLDL) }\end{array}$ & Mostly triglycerides & ApoB 100, ApoC II, ApoC III, ApoE & Major triglyceride carrier \\
\hline Chylomicrons & $\begin{array}{l}\text { Apolipoproteins (2\%) } \\
\text { - Cholesterol (3\%) }\end{array}$ & ApoB 48, ApoC II, ApoC III, ApoE & $\begin{array}{l}\text { Transport of dietary (exogenous) } \\
\text { triglycerides to the systemic } \\
\text { circulation and to adipose tissue } \\
\text { and the liver }\end{array}$ \\
\hline
\end{tabular}

ApoA I, apolipoprotein A I; CETP, cholesteryl ester transfer protein; LCAT, lecithin cholesterol acyltransferase. 
Table 2

Consequences of dyslipidaemia in nephrotic syndrome or CKD

\begin{tabular}{|llll|}
\hline $\begin{array}{l}\text { Complications associated with dyslipidaemia in } \\
\text { nephrotic syndrome }\end{array}$ & $\begin{array}{l}\text { Estimates of individual and additive risk for complications occurring in different } \\
\text { disease states }\end{array}$ & CKD & $\begin{array}{l}\text { Nephrotic syndrome and } \\
\text { CKD }\end{array}$ \\
\cline { 2 - 4 } Nephrotic syndrome & & + \\
\hline Cardiovascular disease & ++ & + & +++ \\
\hline Atherosclerosis & ++ & + & +++ \\
\hline Myocardial infarction & ++ & ++ \\
\hline Cerebrovascular accident (stroke) & & + & + \\
\hline Progressive kidney disease & ++ & + & + \\
\hline Glomerulosclerosis & + & + & ++ \\
\hline$\bullet$ Mesangial cell proliferation & + & + & +++ \\
\hline$\bullet$ Podocyte injury & ++ & + & ++ \\
\hline Tubulointerstitial disease & + & & + \\
\hline$\bullet$ Proximal tubular cell injury & & + & ++ \\
\hline Other & ++ & + \\
\hline Thromboembolism & + & + \\
\hline
\end{tabular}

\pm , minimal risk; +, low risk; ++, moderate risk; +++, high risk; CKD, chronic kidney disease. 
Table 3

Clinical trials and studies of dyslipidaemia treatments in patients with nephrotic syndrome

\begin{tabular}{|c|c|c|c|c|}
\hline Treatment & Action & Outcomes & Limitations & Refs or trials \\
\hline $\begin{array}{l}\text { Conservative lifestyle } \\
\text { changes (diet, weight, } \\
\text { exercise) }\end{array}$ & $\begin{array}{l}-\downarrow \text { Cholesterol } \\
-\downarrow \text { Apolipoproteins (small } \\
\text { reduction) } \\
\cdot \downarrow \text { Triglycerides }\end{array}$ & $\begin{array}{l}\text { - } \downarrow \text { Hyperlipidaemia } \\
\text { • } \downarrow \text { Proteinuria }\end{array}$ & $\begin{array}{l}\text { Implementation and } \\
\text { patient compliance }\end{array}$ & $121-123$ \\
\hline Statins & • $\downarrow$ HMG CoA & $\begin{array}{l}\cdot \downarrow \text { LDL } \\
\cdot \downarrow \text { Cholesterol } \\
\text { - } \text { Triglycerides } \\
\text { - } \uparrow \text { HDL } \\
\text { - Few adverse effects } \\
\text { - Improved cardiovascular } \\
\text { outcome in CKD }\end{array}$ & $\begin{array}{l}\text { Limited number of } \\
\text { studies }\end{array}$ & $\begin{array}{l}\text { 125-131,139*,140*, } \\
\text { NCT00004466* } \\
\text { (REF. 157), } \\
\text { NCT01845428 (REF. } \\
\text { 158) }\end{array}$ \\
\hline Bile acid sequestrants & $\begin{array}{l}\text { - } \downarrow \text { Enterohepatic bile acid } \\
\text { circulation }\end{array}$ & $\bullet \downarrow$ LDL & $\begin{array}{l}\text { - Gastrointestinal } \\
\text { adverse effects } \\
\text { - Less effective than } \\
\text { statins }\end{array}$ & 133 \\
\hline Fibrates & - $\uparrow$ Lipoprotein lipase activity & $\begin{array}{l}-\downarrow \text { Triglycerides } \\
\text { - } \downarrow \text { LDL } \\
\text { - } \downarrow \text { Cholesterol }\end{array}$ & $\begin{array}{l}\text { Meta-analysis found a } \\
\text { lack of support for } \\
\text { fibrate efficacy }\end{array}$ & $112,134,135$ \\
\hline LDL-apheresis & $\begin{array}{l}\cdot \downarrow \text { LDL } \\
\cdot \downarrow \text { Cholesterol } \\
\cdot \downarrow \text { Triglycerides } \\
\cdot \uparrow \text { Response to } \\
\text { immunosuppressants }\end{array}$ & $\begin{array}{l}\text { - Complete or partial } \\
\text { remission of nephrotic } \\
\text { syndrome } \\
\text { - Few adverse effects }\end{array}$ & $\begin{array}{l}\text { Requires central } \\
\text { venous access }\end{array}$ & $\begin{array}{l}141^{*}, 142-144, \\
\text { NCT02235857* } \\
\text { (REF. 154) }\end{array}$ \\
\hline $\begin{array}{l}\text { - Anti PCSK9 antibodies } \\
\text { PCSK9RNA } \\
\text { interference }\end{array}$ & $\begin{array}{l}\text { - Inactivation of PCSK9 } \\
\text { - Degradation of PCSK } 9 \\
\text { mRNA } \\
\text { - } \uparrow \text { Hepatic LDLR }\end{array}$ & $\bullet \downarrow \mathrm{LDL}$ & Very expensive & $\begin{array}{l}44 \neq, \text { NCT03004001 } \\
\text { (REF. 149), } \\
\text { NCT02314442 } \neq \\
\text { (REF. 146) }\end{array}$ \\
\hline
\end{tabular}

* Studies or trials with paediatric patients.

${ }^{*}$ Not in nephrotic syndrome setting. CKD, chronic kidney disease; HDL, high density lipoprotein; HMG CoA, 3 hydroxy 3 methyl glutaryl coenzyme A; LDL, low density lipoprotein; LDLR, LDL receptor; PCSK9, proprotein convertase subtilisin/kexin type 9. 